\title{
Assessment of Laminar, Convective Aeroheating Prediction Uncertainties for Mars Entry Vehicles
}

\author{
Brian R. Hollis* \\ NASA Langley Research Center, Hampton, VA, 23681 \\ Dinesh K. Prabhu ${ }^{\dagger}$ \\ ERC Inc., NASA Ames Research Center, Moffett Field, CA 94035
}

\begin{abstract}
An assessment of computational uncertainties is presented for numerical methods used by NASA to predict laminar, convective aeroheating environments for Mars entry vehicles. A survey was conducted of existing experimental heat-transfer and shock-shape data for high enthalpy, reacting-gas $\mathrm{CO}_{2}$ flows and five relevant test series were selected for comparison to predictions. Solutions were generated at the experimental test conditions using NASA state-of-the-art computational tools and compared to these data. The comparisons were evaluated to establish predictive uncertainties as a function of total enthalpy and to provide guidance for future experimental testing requirements to help lower these uncertainties.
\end{abstract}

\section{Nomenclature}

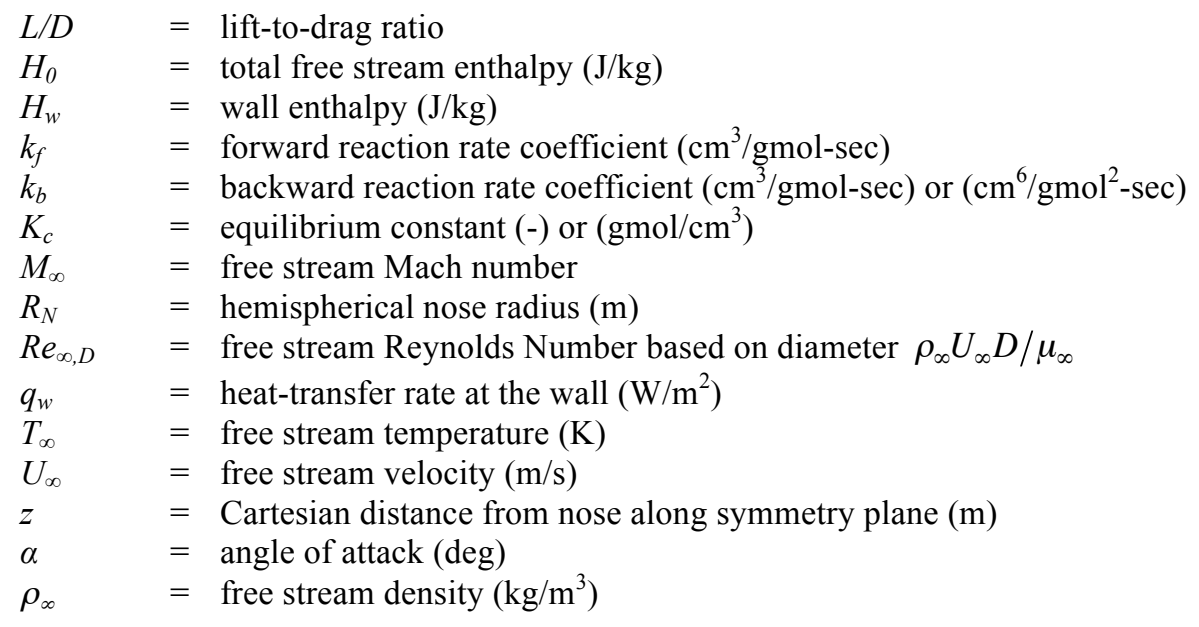

\section{Background}

Two important goals for NASA's future Mars exploration programs are to perform a robotic sample return mission and to enable human exploration missions. Both goals require the safe landing of much greater masses (in excess of 10 metric tons) than those of previous Mars missions. However, the heritage technology employed in past NASA missions from Viking to Mars Science Laboratory (MSL), that of a rigid, 70-sphere-cone, ablative Thermal Protection System (TPS), will not be sufficient to accomplish such new missions. Thus, an Entry, Descent and Landing Systems Analysis Study (EDL-SA) was conducted (Ref. 1) which defined three entry-vehicle architectures that could provide the required increased mass capability. These High-Mass, Mars Entry System (HMMES) architectures are: 1) a mid-range lift-to-drag ratio $(L / D=0.4$ to 0.6$)$ vehicle with a rigid aeroshell; 2) a large, Hypersonic and/or Supersonic Inflatable Aerodynamic Decelerator System (HIADS and SIADS) for high-altitude aerobraking; and 3) hypersonic and/or supersonic retro-propulsion. Mixed architectures that consist of combinations of these elements were also considered. In Figure 1, these three main vehicle classes are shown as Architectures 13 , and various combinations thereof are shown as Architectures 4 - 8. Conceptual illustrations for the mid $L / D$ aeroshell, inflatable aerodynamic decelerator, and hypersonic/supersonic retro-propulsion system are shown in Figure 2 - Figure 4.

\footnotetext{
* Aerospace Engineer, Aerothermodynamics Branch, Associate Fellow AIAA.

${ }^{\dagger}$ Senior Research Scientist, Aerothermodynamics Branch, Associate Fellow AIAA.
} 
In order to insure the safety and success of such missions, the uncertainties in the modeling and prediction of the aerothermodynamic environment, which includes the surface heat-transfer, pressure and shear and the integrated aerodynamic forces and moments that the entry vehicle will experience, must be defined. A step toward fulfilling this requirement is presented in this study, which was performed as part of a larger activity (Ref. 2) sponsored by NASA's Fundamental Aeronautics Program, Hypersonics Project to define, and ultimately reduce, aerothermodynamic uncertainties for several hypersonic mission types. A variety of physical phenomena that influence the HMMES aerothermodynamic environment have been identified. These include, but are not limited to: boundary-layer transition; TPS blowing, ablation and roughness; shock-layer radiation; flexible structure / flow-field interactions; retro-propulsion thruster and reaction control system jet / flow-field and jet / surface interactions; noncontinuum effects at high-altitude and in separated wake flows; surface catalysis; non-equilibrium gas kinetics; etc. A discussion of many of these phenomena and of computational methods used for modeling them is presented in Ref. 3. The sensitivities of these computational methods to input parameters for numerical models of physical phenomena - as distinct from uncertainties determined through comparison to experimental data, which is the subject of this report - have been explored in Ref. 4.

The current study is limited to uncertainties in the prediction of laminar, attached, high-enthalpy flow of $\mathrm{CO}_{2}$ over smooth, non-ablating surfaces. These restrictions define the most basic validation case (short of perfect-gas flow) relevant to Mars missions. Without a thorough understanding of the computational uncertainties in the modeling of these phenomena, uncertainties in modeling other phenomena, such as turbulence, roughness and radiation, cannot properly be addressed.

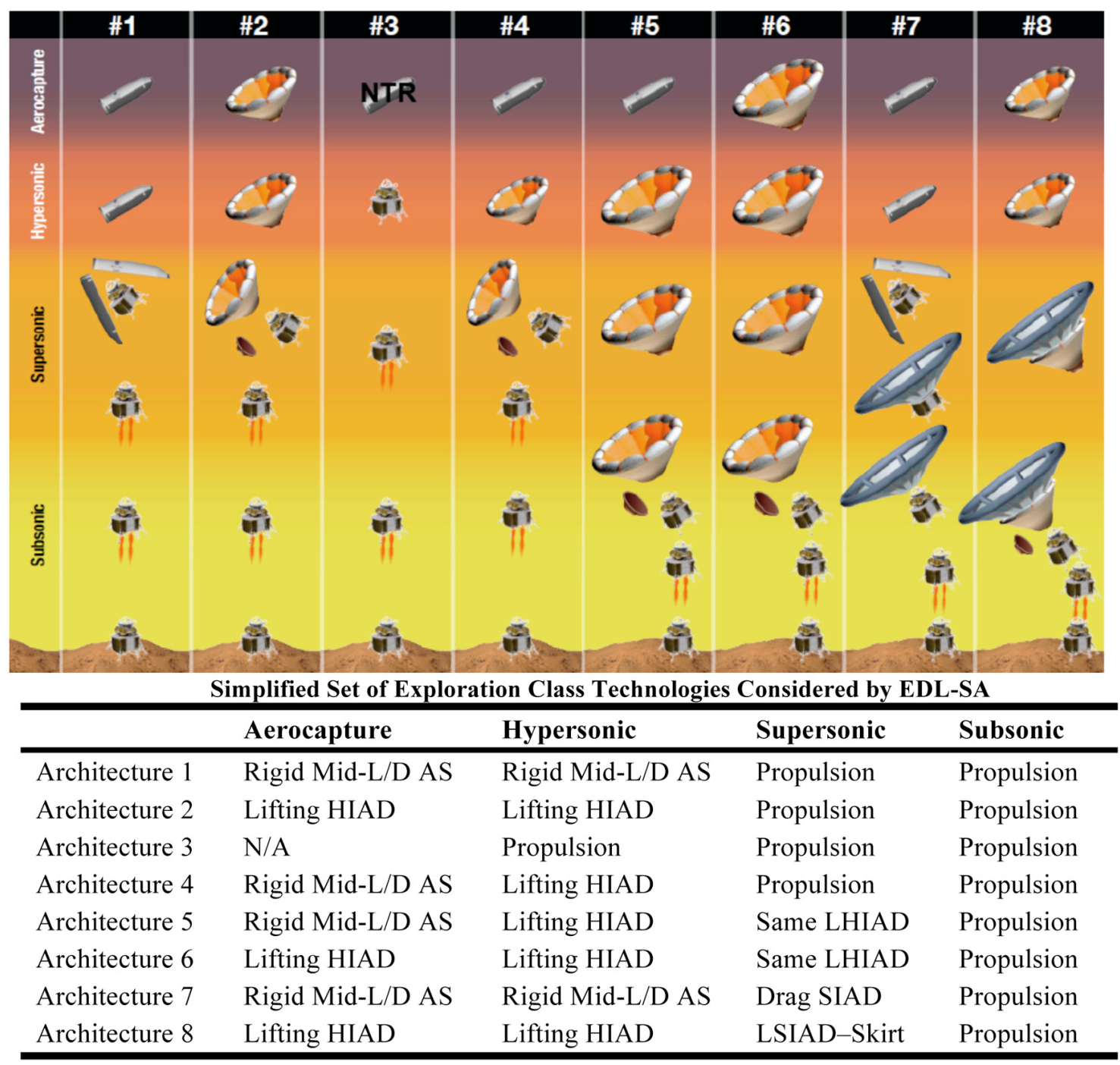

Figure 1. HMMES Architecture Options

2

American Institute of Aeronautics and Astronautics 


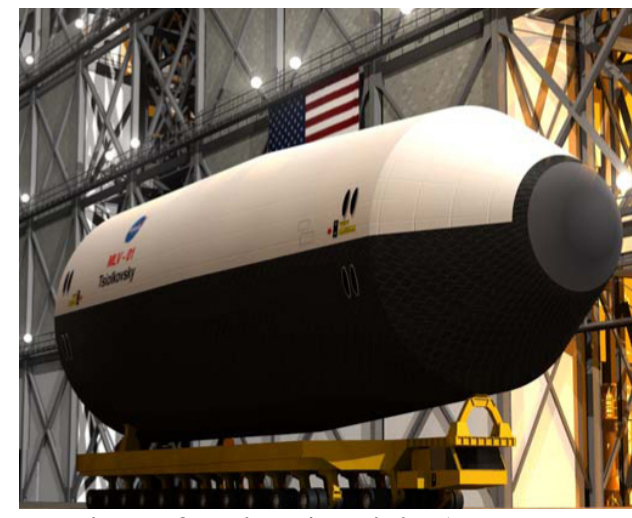

Figure 2. Mid L/D Rigid Aeroshell

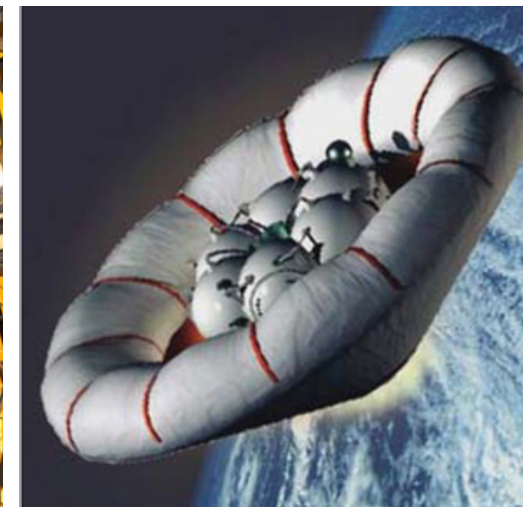

Figure 3. Inflatable Aerodynamic Decelerator

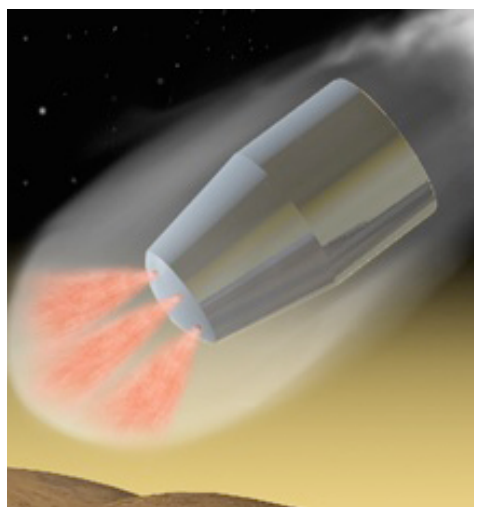

Figure 4. Supersonic RetroPropulsion System

The approach followed to define the uncertainties for laminar, attached, high-enthalpy $\mathrm{CO}_{2}$ flows was:

1) Identify relevant sources of experimental data - i.e. high-enthalpy surface and flow-field test data obtained in $\mathrm{CO}_{2}$ flows. For simplicity, only 0 -deg angle-of-attack data were considered.

2) Generate flow-field predictions at the selected test conditions using the state-of-the-art computational tools currently employed in the development of NASA's Mars missions. Although computations may have been previously performed for some data sets using older software packages, it is important to emphasize that, for the purposes of the current study, new solutions were generated for all cases. The new solutions were generated in order to ensure that a consistent methodology was applied using the latest software versions. Similarly, while other similar software tools exist outside of NASA and have been employed to model such flows, they were not considered in this study.

3) Perform and assess comparisons between the experimental data and numerical results to determine the current state-of-the-art in computational predictions for laminar, high-enthalpy, convective aerothermodynamic environments of Mars missions.

It is expected that the results of this effort to define the state-of-the-art will be used as guidelines for future efforts to reduce the computational uncertainties. Reduction of the modeling uncertainties will require the acquisition of new, high-fidelity experimental ground-test and flight-test data on both macroscopic aerothermodynamics properties (surface heating and pressure, flow-field structure, aerodynamics forces and moments, boundary-layer transition, etc.) and fundamental physical properties (chemical, vibrational, and electronic excitation and relaxation rates, transport properties, and radiation emission and absorption rates). Concurrent development and validation of advanced computational methods and algorithms will also be required.

\section{Review of Experimental Data Applicable to HMMES Missions}

A thorough literature search was performed to identify sources of experimental data relevant to the HMMES uncertainty assessment. Data sets were selected for consideration in which surface heat-transfer measurements were performed in pure $\mathrm{CO}_{2}$ test gas at conditions where post-shock chemical reactions were generated (i.e. in excess of 1 $\mathrm{MJ} / \mathrm{kg}$ ). Although the actual composition of the Martian atmosphere is $\sim 95.3 \% \mathrm{CO}_{2}, 2.7 \% \mathrm{~N}_{2}$ and $2.0 \% \operatorname{Ar}$ (by volume) the kinetics of $\mathrm{CO}_{2}$ are expected to be the greatest uncertainty component because of its predominance, so datasets with $\mathrm{N}_{2}$ (or other minor components) were left to later consideration. Additional data that did not meet the current criteria were also noted for future consideration (e.g. turbulent data, high-enthalpy Air or $\mathrm{N}_{2}$ data).

\section{A. Experimental Data Sets for HMMES Laminar, Convective Uncertainty Assessment}

Five sources of laminar, high-enthalpy, convective heat transfer data in a $\mathrm{CO}_{2}$ environment were identified for inclusion in this study. These data were obtained in the NASA Ames Research Center 42-Inch Shock Tunnel, the GASL HYPULSE Expansion Tube, the Caltech T5 Reflected Shock Tunnel, the University of Illinois Hypervelocity 
Expansion Tube and the CUBRC LENS I Reflected Shock Tunnel. All data are from 70-deg sphere-cone model geometries similar to that of MSL, although there is some variation in nose and corner radius dimensions (relative to the maximum radius) of the models tested.

Test conditions from each of these studies are listed in chronological order in Table 1 and a summary of the wind tunnel model parameters for each test is provided in Table 2. Note that the conditions listed do not necessarily represent all the data obtained in each facility; for simplicity, the data considered herein were limited to 0-deg angleof-attack at laminar conditions. Additional data for non-zero angle of attack and for transitional and turbulent boundary layers are also available in many of these data sets. It is also important to note that these test conditions were actually determined from a combination of experimental flow-field measurements (e.g. shock speed and pitot pressure) and numerical simulation tools (to obtain mass fractions). These numerical tools employ some of the same physical models as do the flow-field codes which are, in theory, to be validated by comparison to the experimental data. Thus, a complete validation exercise, which is outside the scope of this study, would require iterative refinements of test condition predictions and model-in-flow simulations.

The enthalpy/Reynolds number range of the test data is shown in Figure 5. Total enthalpies $\left(H_{0}-H_{\text {wall }}\right)$ ranged from $1.9 \mathrm{MJ} / \mathrm{kg}$ (near to prefect gas) to $12.3 \mathrm{MJ} / \mathrm{kg}$ (non-equilibrium chemistry). Reynolds numbers (based on diameter) for all data considered were less than $10^{6}$, which resulted in laminar conditions for all cases except one partly-transitional run in the CUBRC data set.

For comparison to flight conditions, reference values for HMMES Mid $L / D$ and HIADS configurations are shown on this plot, as well as reference values for the Mars Science Laboratory and Mars Viking missions. It is notable that the MSL reference condition is at the high-end of the range of Reynolds number and enthalpy test conditions, while the HMMES conditions are a factor of 2 to 3 higher in enthalpy and an order of magnitude greater in Reynolds number. In contrast, the peak heating condition for the Mars Viking mission is well within the range of test conditions.

\section{NASA ARC 42-Inch Shock Tunnel Data}

Data were obtained (Ref. 5) at laminar test conditions on a 70-deg sphere cone model in $\mathrm{CO}_{2}$, Air, and $\mathrm{CO}_{2}-\mathrm{Ar}$ environments in the NASA Ames Research Center 42-Inch Shock Tunnel (also sometimes referred to as the Ames $3.5 \mathrm{ft}$ Shock Tunnel). The facility (since demolished) was a combustion-heated, reflected shock tunnel with 10-20 millisecond test times. Heat transfer data and flow field schlieren images were obtained on copper models instrumented with surface thermocouples. Three separate configurations were actually tested. All were 70-deg sphere-cones geometries with 1.5-inch nose radii; however, the model had interchangeable outer sections with various corner radii that resulted in 2.74-in. to 2.99-in. max-radius models. Besides the 0-deg angle-of-attack runs considered herein, additional runs were performed at $\alpha=10$-deg and 20-deg. An experimental uncertainty of $\pm 10 \%$ was cited for the heating data from this study.

\section{GASL HYPULSE Expansion Tube Data}

Testing was performed (Refs. 6, 7, 8) in the GASL (now ATK) HYPULSE Expansion tube on 70-deg spherecone models of 1.00 maximum radius in air and $\mathrm{CO}_{2}$ test gases. Laminar data were obtained on three 70-deg sphere-cone models of varying corner radii and on a blunted hyperboloid with 70-deg asymptotes. The models were fabricated from Macor ceramic and instrumented with thin-film heat-flux gages. In addition to the $\alpha=0$ data considered herein, data are also available for 4-deg and 8-deg angles of attack. An experimental uncertainty of $\pm 11 \%$ was cited for the heating data from this study.

\section{Caltech T5 Reflected Shock Tunnel Data}

Heat-transfer tests were performed (Refs. 9, 10) on a 3.50-in maximum radius, 70-deg sphere-cone model in the Caltech T5 Reflected Shock Tunnel in $\mathrm{CO}_{2}$ and $\mathrm{N}_{2}$ test gases. The model was fabricated from stainless steel and instrumented with fast-response coaxial thermocouples. Testing was performed at angles of attack of 0-deg, 11-deg and 16-deg and laminar, transitional and turbulent data were produced, although only laminar, 0-deg runs are considered herein. While a specific value for experimental uncertainty was not cited for the $\mathrm{CO}_{2}$ data of Ref. 9 , error-bars shown on the plots were approximately $\pm 11 \%$.

\section{CUBRC LENS I Reflected Shock Tunnel Data}

Measurements on MSL geometry models were performed in $\mathrm{CO}_{2}$ in the CUBRC LENS I Reflected Shock Tunnel. Two test series were performed: the first with a thermocouple and thin-film instrumented, 12-inch 
maximum radius model (Refs. 11-12) and the second with a 6-inch maximum radius model instrumented with thinfilm gages, coaxial thermocouples, and silver calorimeters (Ref. 13). Both models were fabricated from stainless steel. In addition to the 0 -deg angle-of-attack data consider herein, runs were also made at $\alpha=11$-deg, 16 -deg and 20-deg that produced laminar, transitional and turbulent flows. While specific values for experimental uncertainties for each gage type were not given, error-bars shown on plots in Ref. 13 were approximately $\pm 5 \%$ to \pm 10 .

\section{University of Illinois Hypervelocity Expansion Tube Data}

The most recent data available (Ref. 14) were obtained in the University of Illinois Hypervelocity Expansion Tube (HET). The test geometry was a 1.00-inch maximum radius, 70-deg sphere-cone stainless steel model instrumented with fast-response coaxial thermocouples. Laminar data were obtained at angles-of-attack of 0-deg, 11-deg and 16-deg. An uncertainty of $\pm 8 \%$ was cited for the coaxial gage measurements but an overall experimental uncertainty was not given.

Table 1. Test Conditions

\begin{tabular}{|c|c|c|c|c|c|c|c|c|c|c|}
\hline \multirow[b]{2}{*}{ Facility } & \multirow{2}{*}{$\begin{array}{l}\text { Facility } \\
\text { type }\end{array}$} & \multirow{2}{*}{$\begin{array}{c}\rho_{\infty} \\
\left(\mathrm{kg} / \mathrm{m}^{3}\right)\end{array}$} & \multirow{2}{*}{$\begin{array}{l}\mathbf{T}_{\infty} \\
(\mathbf{K})\end{array}$} & \multirow{2}{*}{$\begin{array}{c}\mathbf{U}_{\infty} \\
(\mathbf{m} / \mathbf{s})\end{array}$} & \multirow[b]{2}{*}{$\mathbf{R e}_{\infty, \mathbf{D}}$} & \multirow{2}{*}{$\begin{array}{c}\mathrm{H}_{\mathbf{0}}-\mathrm{H}_{\mathrm{w}} \\
(\mathrm{MJ} / \mathbf{k g})\end{array}$} & \multicolumn{4}{|c|}{ Free stream mass fractions } \\
\hline & & & & & & & {$\left[\mathrm{CO}_{2}\right]$} & {$[\mathbf{C O}]$} & {$\left[\mathbf{O}_{2}\right]$} & [0] \\
\hline $\begin{array}{l}\text { NASA Ames 42-Inch } \\
\text { Shock Tunnel }\end{array}$ & $\begin{array}{l}\text { Reflected shock } \\
\text { tunnel }\end{array}$ & $3.10 \times 10^{-4}$ & 200 & 4150 & $0.25 \times 10^{6}$ & 8.5 & 1.000 & 0.000 & 0.000 & 0.000 \\
\hline $\begin{array}{c}\text { GASL HYPULSE } \\
\text { (Runs 747, 749) }\end{array}$ & $\begin{array}{c}\text { Shock expansion } \\
\text { tube }\end{array}$ & $5.79 \times 10^{-3}$ & 1088 & 4772 & $0.93 \times 10^{6}$ & 12.3 & 1.000 & 0.000 & 0.000 & 0.000 \\
\hline $\begin{array}{l}\text { Caltech T5 } \\
\text { (Run 2256) }\end{array}$ & $\begin{array}{l}\text { Reflected shock } \\
\text { tunnel }\end{array}$ & $5.70 \times 10^{-2}$ & 1407 & 2732 & $1.67 \times 10^{6}$ & 6.1 & 0.831 & 0.108 & 0.061 & 0.000 \\
\hline $\begin{array}{l}\text { Cal Tech T5 } \\
\text { (Run 2254) }\end{array}$ & $\begin{array}{l}\text { Reflected shock } \\
\text { tunnel }\end{array}$ & $3.12 \times 10^{-2}$ & 1828 & 3367 & $1.25 \times 10^{6}$ & 10.6 & 0.550 & 0.287 & 0.151 & 0.012 \\
\hline $\begin{array}{l}\text { Caltech T5 } \\
\text { (Run 2255) }\end{array}$ & $\begin{array}{l}\text { Reflected shock } \\
\text { tunnel }\end{array}$ & $7.83 \times 10^{-2}$ & 2188 & 3514 & $2.26 \times 10^{6}$ & 11.3 & 0.592 & 0.259 & 0.139 & 0.009 \\
\hline $\begin{array}{l}\text { CUBRC LENS I } \\
\text { (Series 1, Run 12) }\end{array}$ & $\begin{array}{l}\text { Reflected shock } \\
\text { tunnel }\end{array}$ & $5.26 \times 10^{-4}$ & 691 & 2761 & $0.29 \times 10^{6}$ & 4.9 & 0.901 & 0.063 & 0.036 & 0.00 \\
\hline $\begin{array}{l}\text { CUBRC LENS I } \\
\text { (Series 2, Run 16) }\end{array}$ & $\begin{array}{l}\text { Reflected shock } \\
\text { tunnel }\end{array}$ & $1.48 \times 10^{-2}$ & 361 & 1907 & $0.94 \times 10^{6}$ & 1.9 & 1.000 & 0.000 & 0.000 & 0.000 \\
\hline $\begin{array}{l}\text { CUBRC LENS I } \\
\text { (Series 2, Run 12) }\end{array}$ & $\begin{array}{l}\text { Reflected shock } \\
\text { tunnel }\end{array}$ & $8.70 \times 10^{-3}$ & 931 & 2939 & $0.77 \times 10^{6}$ & 6.0 & 0.843 & 0.100 & 0.057 & 0.000 \\
\hline $\begin{array}{l}\text { CUBRC LENS I } \\
\text { (Series 2, Run 08) }\end{array}$ & $\begin{array}{l}\text { Reflected shock } \\
\text { tunnel }\end{array}$ & $8.96 \times 10^{-3}$ & 892 & 2870 & $0.21 \times 10^{6}$ & 5.6 & 0.863 & 0.087 & 0.05 & 0.000 \\
\hline $\begin{array}{c}\text { CUBRC LENS I } \\
\text { (Series 2, Run 13) }\end{array}$ & $\begin{array}{c}\text { Reflected shock } \\
\text { tunnel }\end{array}$ & $6.06 \times 10^{-3}$ & 1116 & 3373 & $0.16 \times 10^{6}$ & 8.6 & 0.687 & 0.199 & 0.110 & 0.003 \\
\hline $\begin{array}{c}\text { University of Illinois } \\
\text { HET }\end{array}$ & $\begin{array}{c}\text { Shock expansion } \\
\text { tube }\end{array}$ & $1.44 \times 10^{-2}$ & 1172 & 3058 & $0.43 \times 10^{6}$ & 5.7 & 1.000 & 0.000 & 0.000 & 0.000 \\
\hline
\end{tabular}


Table 2. Wind Tunnel Model Information

\begin{tabular}{|c|c|c|c|c|c|c|c|}
\hline Facility & $\begin{array}{c}\text { Max } \\
\text { radius } \\
\text { (in) }\end{array}$ & $\begin{array}{c}\text { Nose } \\
\text { Radius } \\
\text { (in) }\end{array}$ & $\begin{array}{l}\text { Corner } \\
\text { Radius } \\
\quad \text { (in) }\end{array}$ & $\begin{array}{l}\text { Cone } \\
\text { angle } \\
\text { (deg) }\end{array}$ & $\begin{array}{c}\text { Model } \\
\text { Instrumentation }\end{array}$ & $\begin{array}{c}\text { Model } \\
\text { Material }\end{array}$ & Refs. \\
\hline $\begin{array}{l}\text { NASA Ames 42-Inch } \\
\text { Shock Tunnel }\end{array}$ & $\begin{array}{l}A=2.74 \\
B=2.82 \\
C=2.99\end{array}$ & $\begin{array}{l}A=1.5 \\
B=1.5 \\
C=1.5\end{array}$ & $\begin{array}{l}\mathrm{A}=0.039 \\
\mathrm{~B}=0.167 \\
\mathrm{C}=0.470\end{array}$ & 70 & $\begin{array}{l}\text { Surface junction } \\
\text { thermocouples }\end{array}$ & Copper & Ref. 5 \\
\hline GASL HYPULSE & 1.00 & 0.5 & $\begin{array}{l}M P 1=0.05 \\
M P 3=0.10 \\
M P 4=0.20\end{array}$ & 70 & $\begin{array}{c}\text { Thin-film temperature } \\
\text { gages }\end{array}$ & $\begin{array}{l}\text { Macor } \\
\text { Ceramic }\end{array}$ & Refs. $6,7,8$ \\
\hline Caltech T5 & 3.50 & 1.75 & 0.35 & 70 & $\begin{array}{l}\text { Fast-response coaxial } \\
\text { thermocouples }\end{array}$ & $\begin{array}{c}\mathrm{SS} 304 \\
\text { stainless steel }\end{array}$ & Ref. 9, 10 \\
\hline $\begin{array}{c}\text { CUBRC LENS I - } \\
\text { Series } 1\end{array}$ & 12.0 & 6.0 & 0.60 & 70 & $\begin{array}{l}\text { Thin-film temperature } \\
\text { gages and coaxial } \\
\text { thermocouples }\end{array}$ & Stainless steel & Refs. 11,12 \\
\hline $\begin{array}{c}\text { CUBRC LENS I - } \\
\text { Series } 2\end{array}$ & 6.0 & 3.0 & 0.30 & 70 & $\begin{array}{l}\text { Coaxial thermocouples, } \\
\text { thin-film temperature } \\
\text { gages and silver } \\
\text { calorimeters }\end{array}$ & Stainless steel & Ref. 13 \\
\hline $\begin{array}{c}\text { University of Illinois } \\
\text { HET }\end{array}$ & 1.00 & 0.5 & 0.05 & 70 & $\begin{array}{l}\text { Fast-response coaxial } \\
\text { thermocouples }\end{array}$ & $\begin{array}{l}\text { AI } 2024 \text { and } \\
\text { A2 tool steel }\end{array}$ & Ref. 14 \\
\hline
\end{tabular}

B. Other relevant sources of highenthalpy convective aeroheating data

Other sources for high-enthalpy aeroheating data sets exist that may be of use in defining uncertainties in nonequilibrium kinetic models even though these data were not obtained in pure $\mathrm{CO}_{2}$ flows. These include, as previously noted: $\mathrm{CO}_{2}-\mathrm{Ar}$ and Air data from the Ames Research Center 42-Inch Shock Tunnel (Ref. 5); Air data from GASLHYPULSE (Refs. 6-8) and $\mathrm{N}_{2}$ data from Caltech T5 (Ref. 10).

Other blunt-cone aeroheating data were obtained in several facilities as part of the NATO AGARD Working Group 18 activity (Ref. 15). While the primary purpose of this program was to obtain rarefied wake flow data (Ref. 16), highenthalpy forebody aeroheating data were also generated in two of the tests (Ref. 17): those conducted at DLR-HEG and CUBRC LENS.

The DLR-HEG tests was conducted on a 70-deg sphere-cone model with highenthalpy runs in air, $\mathrm{CO}_{2}$, and $\mathrm{CO}_{2}-\mathrm{N}_{2}$ mixtures. Unfortunately, explicit information regarding free-stream specie mass concentrations is incomplete in the documentation available (Refs. 18 - 20). As it was not within the scope of this study to perform computations to determine facility operating

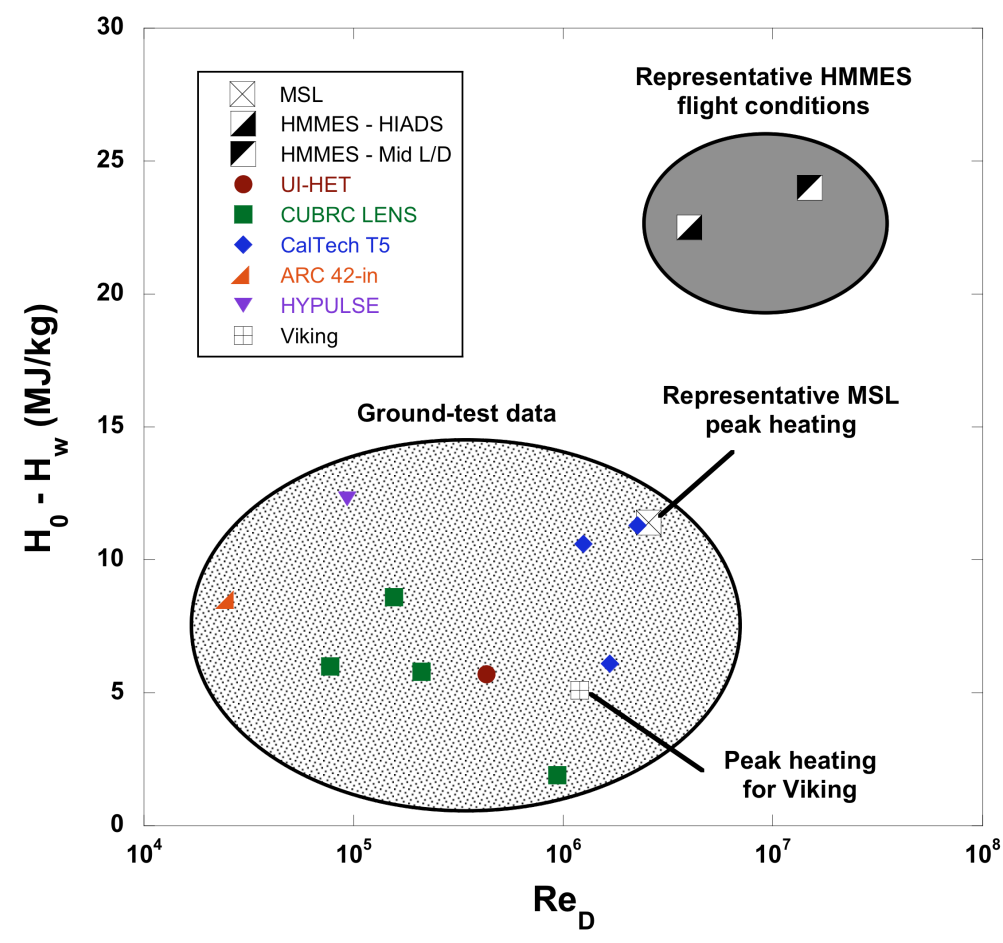

Figure 5. Comparison of Ground Test and Flight Conditions 
conditions, these data were not analyzed. If such information could be obtained, these data should be factored into future work.

The CUBRC LENS AGARD-18 test was conducted on a 70-deg sphere-cone model in Air and $\mathrm{N}_{2}$ at enthalpies between $5 \mathrm{MJ} / \mathrm{kg}$ and $10 \mathrm{MJ} / \mathrm{kg}$. Data were obtained (Ref. 21) on both the blunted-cone forebody and in the wake on an instrumented sting.

\section{Computational Methods}

Flow-field solutions were generated at each test condition using NASA's LAURA and DPLR codes. These codes are the two primary numerical simulation tools employed by NASA for continuum hypersonic aerothermodynamic computations and extensive documentation and background material are available (e.g. Refs. 22-23 and 24-25) for each code. Although there are some algorithmic and physical modeling differences between them, both are structured-grid Navier-Stokes solvers for flows with vibrational and chemical non-equilibrium. Past code-to-code comparisons have demonstrated good agreement between them for entry vehicle aerothermodynamic simulations relevant to HMMES, such as for the Mars Science Laboratory (Ref. 26) and Fire II (Ref. 27) missions.

In this study, the physical model employed was that of laminar flow, with two-temperature (translational \& vibrational/electronic) representation and non-equilibrium chemical kinetics. A five-reaction chemistry model for the $\mathrm{CO}_{2}-\mathrm{CO}-\mathrm{O}_{2}-\mathrm{O}-\mathrm{C}$ system was used, with forward reactions as defined by the modified Arrhenius form of Eq. 1 and backward rates determined from the equilibrium constant definition via Eq. 2. The forward reaction coefficients are listed in Table 3. The carbon atom producing reactions (\#1 and \#2) were included in this set for completeness; however, these reactions were found to be negligible for the range of test conditions considered.

$$
\begin{gathered}
k_{F}=A \times T^{B} \times \exp (-C / T) \text { units of }\left(\frac{\mathrm{cm}^{3}}{\mathrm{gmol}-\mathrm{s}}\right) \\
k_{B}=\frac{k_{F}}{K_{C}} \text { units of }\left(\frac{\mathrm{cm}^{6}}{\mathrm{gmol}^{2}-s}\right) \text { or }\left(\frac{\mathrm{cm}^{3}}{\mathrm{gmol}-s^{-s}}\right)
\end{gathered}
$$

Table 3. Forward Reaction Rate Coefficients

\begin{tabular}{|c|c|ccc|c|c|c|}
\hline$\#$ & Reaction & A & B & C & Type & Third-party multiplier & Ref. \\
\hline 1 & $\mathrm{CO}+\mathrm{M} \rightarrow \mathrm{C}+\mathrm{O}+\mathrm{M}$ & $2.3 \times 10^{20}$ & -1.00 & $1.29 \times 10^{5}$ & dissociation & & 28 \\
2 & $\mathrm{CO}+\mathrm{O} \rightarrow \mathrm{O}_{2}+\mathrm{C}$ & $3.9 \times 10^{13}$ & -0.18 & $6.92 \times 10^{4}$ & exchange & & \\
3 & $\mathrm{CO}_{2}+\mathrm{M} \rightarrow \mathrm{CO}+\mathrm{O}+\mathrm{M}$ & $1.5 \times 10^{25}$ & -2.50 & $6.60 \times 10^{4}$ & exchange & $\times 2$ for $\mathrm{M}=$ atoms & 30 \\
4 & $\mathrm{CO}_{2}+\mathrm{O} \rightarrow \mathrm{O}_{2}+\mathrm{CO}$ & $2.1 \times 10^{13}$ & 0.00 & $2.78 \times 10^{4}$ & dissociation & & \\
5 & $\mathrm{O}_{2}+\mathrm{M} \rightarrow 2 \mathrm{O}+\mathrm{M}$ & $2.0 \times 10^{21}$ & -1.50 & $5.94 \times 10^{4}$ & dissociation & $\times 5$ for $\mathrm{M}=$ atoms & 29 \\
\hline
\end{tabular}

For the comparisons with experimental data, the free stream boundary conditions were taken from the published facility test conditions. The wall temperature boundary condition was set to a constant $300 \mathrm{~K}$ value; although heattransfer rates for these cases can be very high, the facility run times were in the millisecond to microsecond ranges, over which time the increase in wall temperature was negligible with respect to the boundary-layer edge temperatures. A surface catalysis boundary condition was also required. Several surface catalysis model options were employed: A non-catalytic option, a fully-catalytic option (atoms recombine to diatomics) and a "supercatalytic" option, in which recombination to $100 \% \mathrm{CO}_{2}$ is enforced at the surface. The choice of wall catalysis model has been shown to have a large effect on sensitivity of aeroheating predictions (Ref. 4) but unfortunately, as discussed in Ref. 3, there are little data available at low temperatures (such as generated in these tests) on catalysis effects for $\mathrm{CO}_{2}$ reactions to help justify the selection of a particular catalysis model.

\section{Assessment of Experimental-Computational Comparisons}

\section{A. Surface Heat-Transfer Comparisons}

Comparisons were made between the LAURA and DPLR predictions and the experimental heat-transfer data for each test condition. These comparisons are shown in Figure 6 through Figure 16 and are ordered in terms of 
increasing total enthalpy over the whole set of data, not just on a facility-by-facility basis. In each figure, the experimental data are shown with error bars of $\pm 15 \%$. This value is purely a nominal figure used as a consistent reference and is not derived from the published reports; the actual stated experimental uncertainties varied from approximately $5 \%$ to $15 \%$ as discussed previously. For the computational results, predictions are shown for the noncatalytic, fully-catalytic, and super-catalytic wall boundary condition options. LAURA and DPLR results were generally consistent with differences between them being much smaller than the differences produced by selection of the wall catalysis boundary condition. Thus, in order to maintain clarity on the plots, only the fully-catalytic DPLR results will be shown along with the LAURA results for each boundary condition.

With the exception of the GASL HYPULSE case (which is the highest enthalpy condition), the current comparisons between predictions and measurements are similar to the comparisons previously published for each study. For the GASL HYPULSE case (Figure 16), there is a large over-prediction of the data in the current study that was not evident in the original comparisons. This difference was traced to the chemical-kinetic models employed. In the original study, explicit forward and backward reaction rates were specified as per Ref. 31, whereas in the current study the backward rates were determined from the definition of the equilibrium constant (e.g. Ref. 32). When the chemistry models employed in Refs. 6-8 were substituted into LAURA, similar agreement with the experimental data was observed. This observation is not to intended to imply that one model or the other is "correct", but merely to identify the cause of a discrepancy between current and previous comparisons.

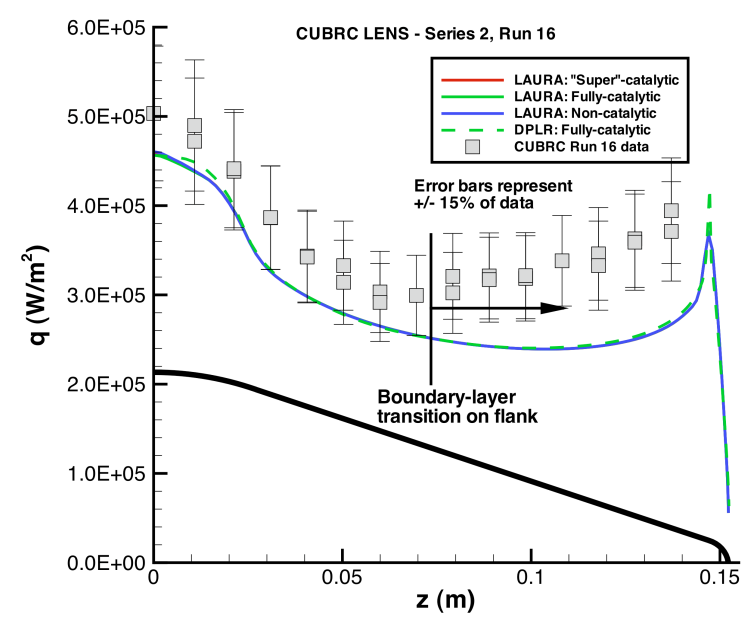

Figure 6. CUBRC LENS I Reflected Shock Tunnel: Series 2, Run 16 - 1.9 MJ/kg case

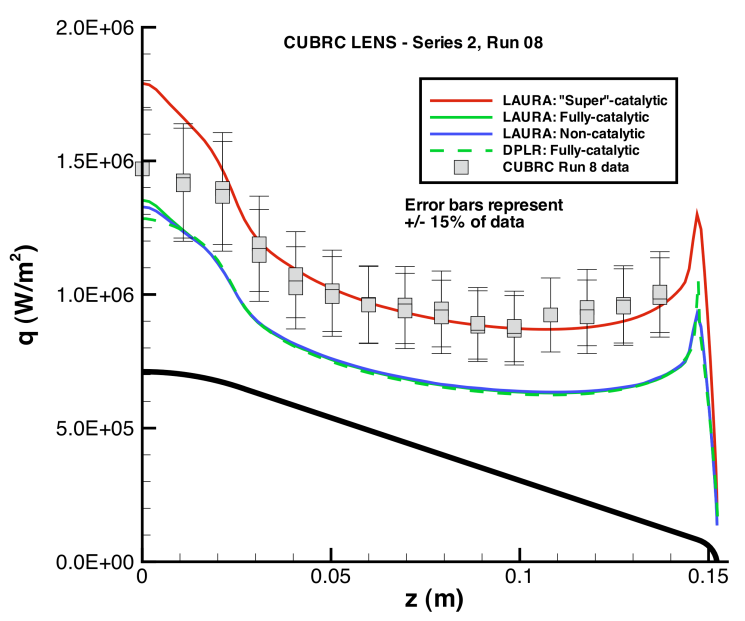

Figure 8. CUBRC LENS I Reflected Shock Tunnel: Series 2, Run 8 - 5.6 MJ/kg case

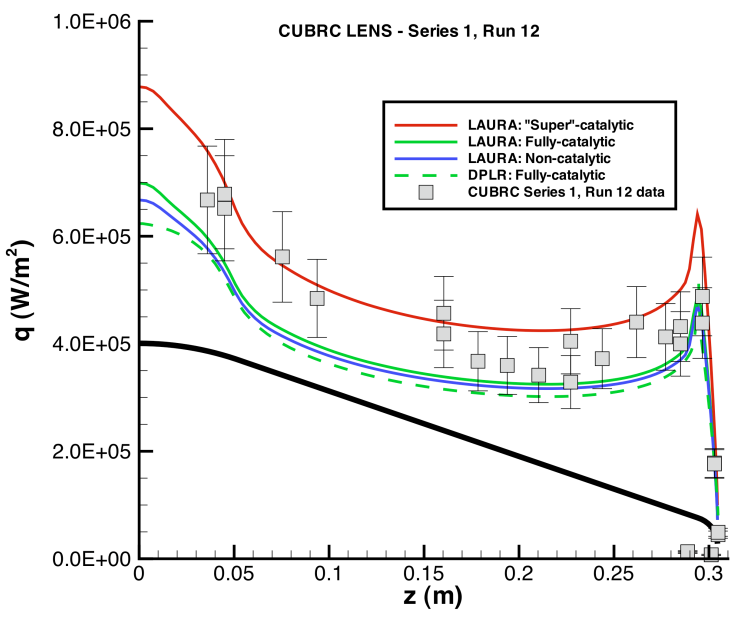

Figure 7. CUBRC LENS I Reflected Shock Tunnel: Series 1, Run 12 - $5.1 \mathrm{MJ} / \mathrm{kg}$ case

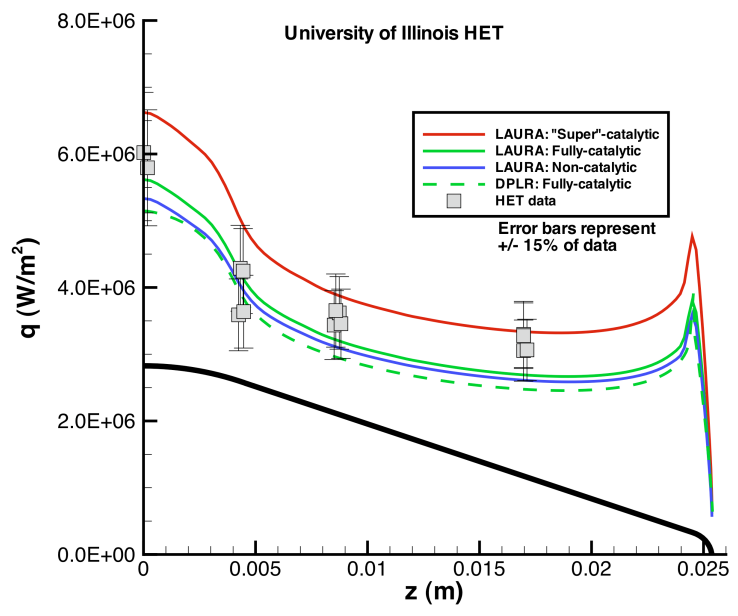

Figure 9. University of Illinois HET Expansion Tube: $5.7 \mathrm{MJ} / \mathrm{kg}$ case

8

American Institute of Aeronautics and Astronautics 


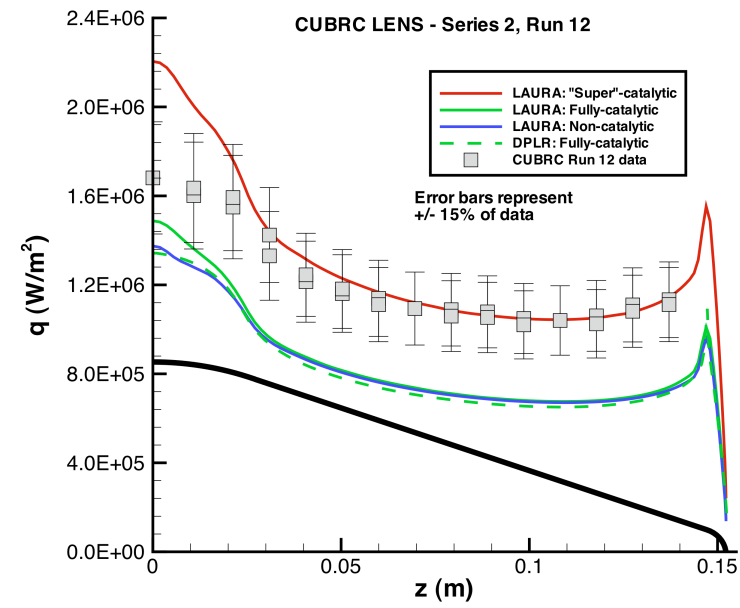

Figure 10. CUBRC LENS I Reflected Shock Tunnel: Series 2, Run $12-6.0 \mathrm{MJ} / \mathrm{kg}$ case

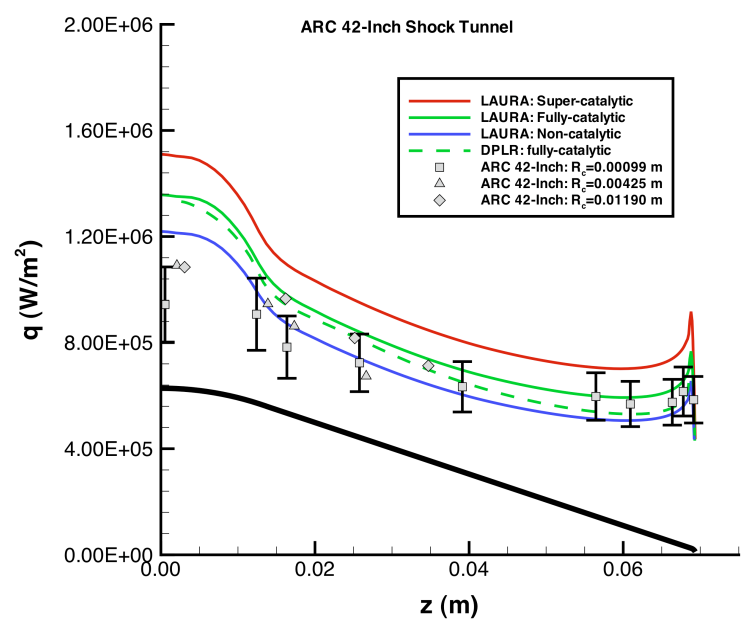

Figure 12. ARC 42-Inch Shock Tunnel - 8.5 $\mathrm{MJ} / \mathrm{kg}$ case

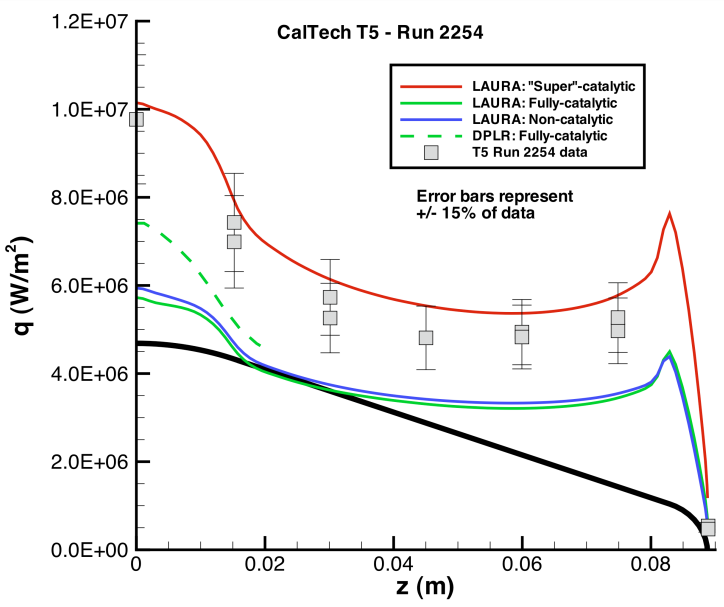

Figure 14. Caltech T5 Reflected Shock Tunnel: Run 2254 - 10.6 MJ/kg case

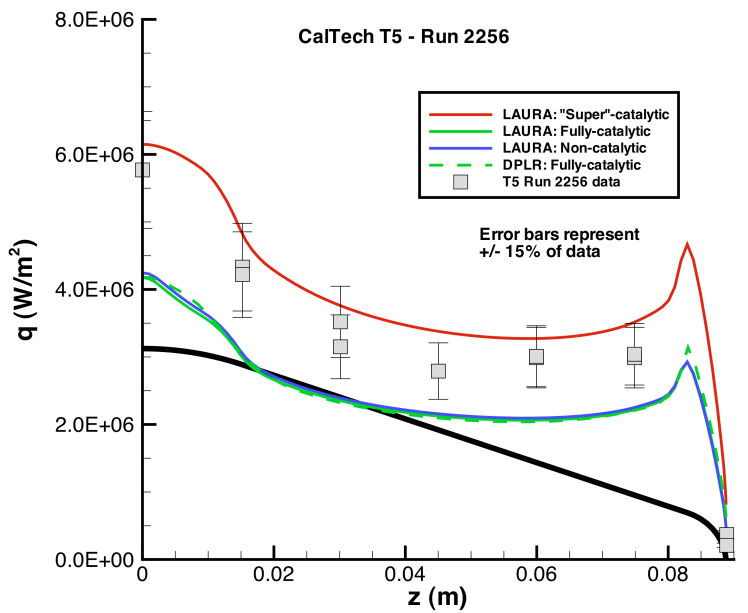

Figure 11. Caltech T5 Reflected Shock Tunnel: Run 2256 - 6.1 MJ/kg case

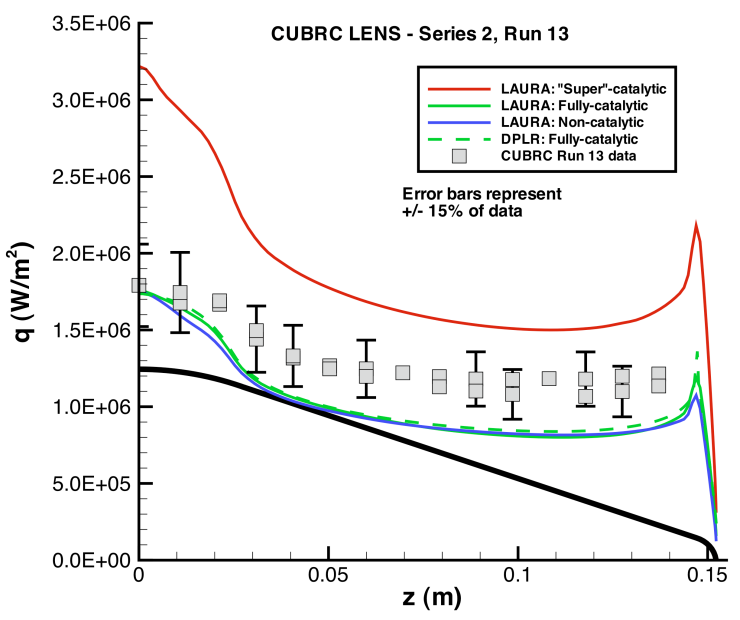

Figure 13. CUBRC LENS I Reflected Shock Tunnel: Series 2, Run $13-8.6 \mathrm{MJ} / \mathrm{kg}$ case

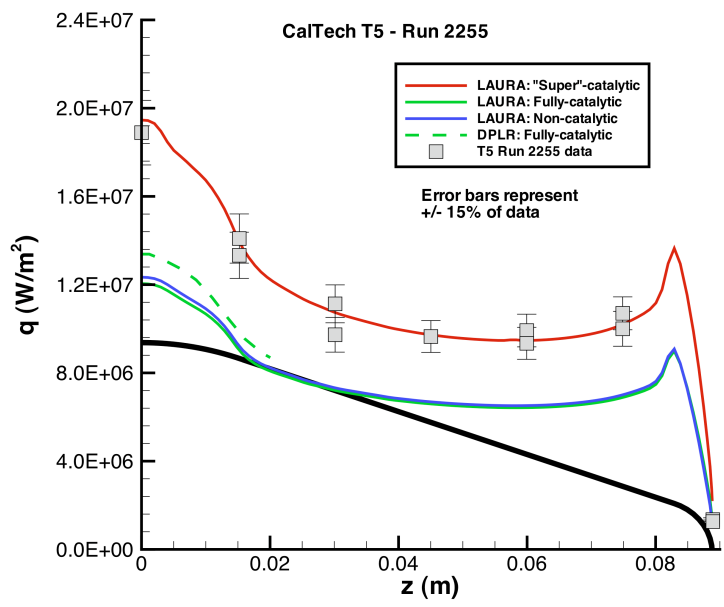

Figure 15. Caltech T5 Reflected Shock Tunnel: Run 2255 - 11.3 MJ/kg case 


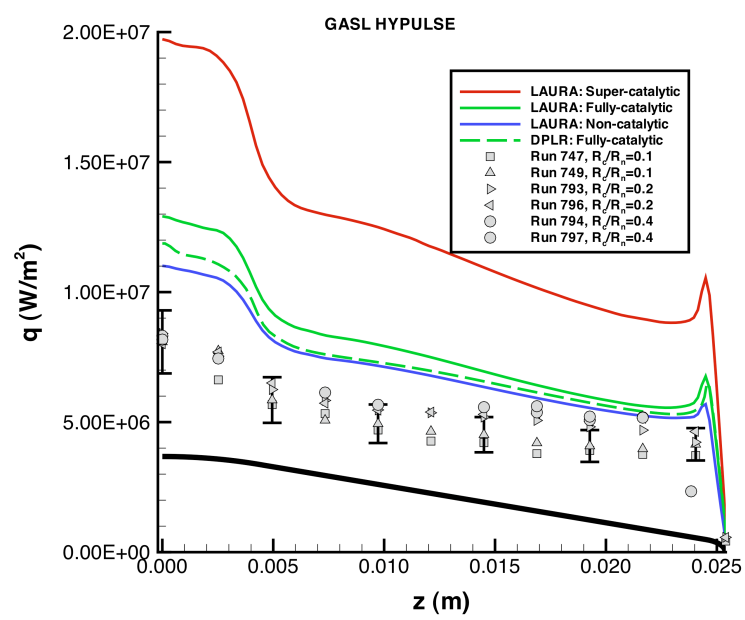

Figure 16. GASL HYPULSE Expansion

Tube: $-12.3 \mathrm{MJ} / \mathrm{kg}$ case

The differences between prediction and measurement shown for each of the gages in Figure 6 - Figure 16 were averaged for each case to determine an overall uncertainty for that case. Averages were generated for supercatalytic and non-catalytic comparison in terms of both the average magnitude (absolute value) of the differences between prediction and measurement and the average of the signed (positive/negative) differences. These averages are plotted in Figure 17 through Figure 20 vs. total enthalpy. From these figures, several general observations can be made:

1) The average magnitude per case of the differences between non-catalytic predictions and experimental data varied between $15 \%$ and $45 \%$.

2) The average magnitude per case of the differences between super-catalytic predictions and experimental data varied between approximately $5 \%$ and $30 \%$, with the exception of a $148 \%$ difference for the GASL HYPULSE case

3) The non-catalytic predictions averaged from approximately $1 \%$ to $35 \%$ lower than the data per case, expect for the GASL HYPULSE case where the predictions were $45 \%$ higher than the data.

4) The super-catalytic predictions averaged from 5\% to 35\% higher than the data per case, with the exception of a 148\% over-prediction for the GASL HYPULSE case and the under-prediction for the lowenthalpy CUBRC LENS case.

5) A linear fit can be made for any of the average comparisons to show that the differences increase with total enthalpy. However, the quality of such fits is questionable given the small number of data points available and the skew resulting from the very large differences for the GASL HYPULSE case.

From these results, it is tempting to conclude that the super-catalytic boundary-condition is appropriate because it provides the closest agreement with the data, with the exception of the GASL HYPULSE case which could be eliminated as an outlier point. In fact, for NASA's MSL mission, this conclusion was applied because the supercatalytic option provides the most design conservatism (Ref. 33).

However, while possibly appropriate as a vehicle design paradigm, such a conclusion cannot be applied to a rigorous uncertainty analysis. Other evidence must also be considered. First, that the limited set of data on $\mathrm{CO}_{2}$ surface catalysis do not support (see Ref. 3) the super-catalytic model for metallic surfaces at low temperatures. Second, that the HYPULSE data were obtained on models fabricated from Macor ceramic, which would be expected to show even less catalytic efficiency than a metallic model; thus this test may provide a distinctly different physical environment than the others and cannot be immediately dismissed. Third, that the free stream environment of the GASL HYPULSE test (and also the University of Illinois HET test) was generated in a significantly different manner than the CUBRC LENS, Caltech T5, and Ames 42-Inch Shock Tunnel tests - the first two facilities operate as shock-expansion tunnels, whereas the other three operate as reflected shock tunnels. As discussed in Ref. 34, there is considerable uncertainty as to the vibrational non-equilibrium state of the free stream in reflected shock tunnels, which could produce significant uncertainties in the results surface heat-transfer measurements. And finally, as will be shown in the next section, regardless of surface catalysis model selected, major differences were also observed in the comparisons between predicted and measured shock shapes. Such flow-field differences cannot be a function of surface catalysis, thus there must be other uncertainty factors to consider. 


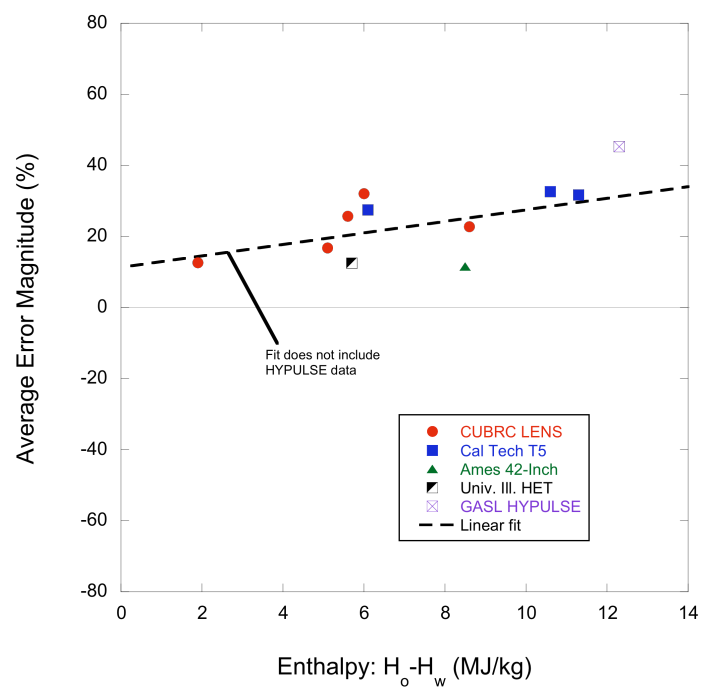

Figure 17. Comparison of non-catalytic predictions to data - averaged error magnitude

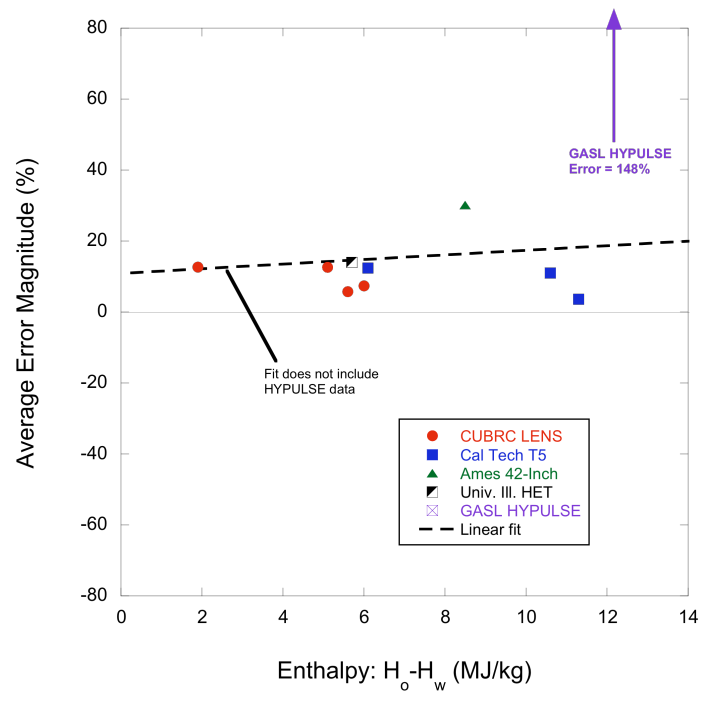

Figure 19. Comparison of super-catalytic predictions to data - averaged error magnitude

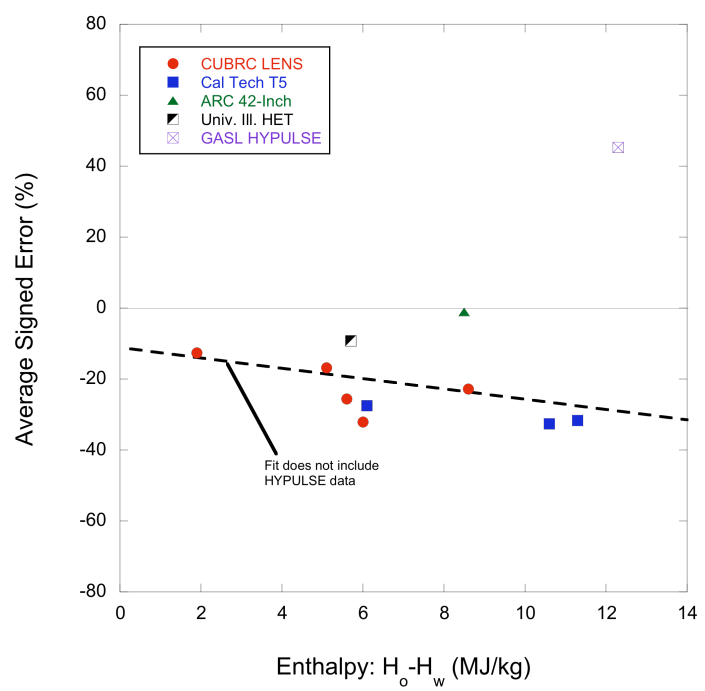

Figure 18. Comparison of non-catalytic predictions to data - averaged signed error

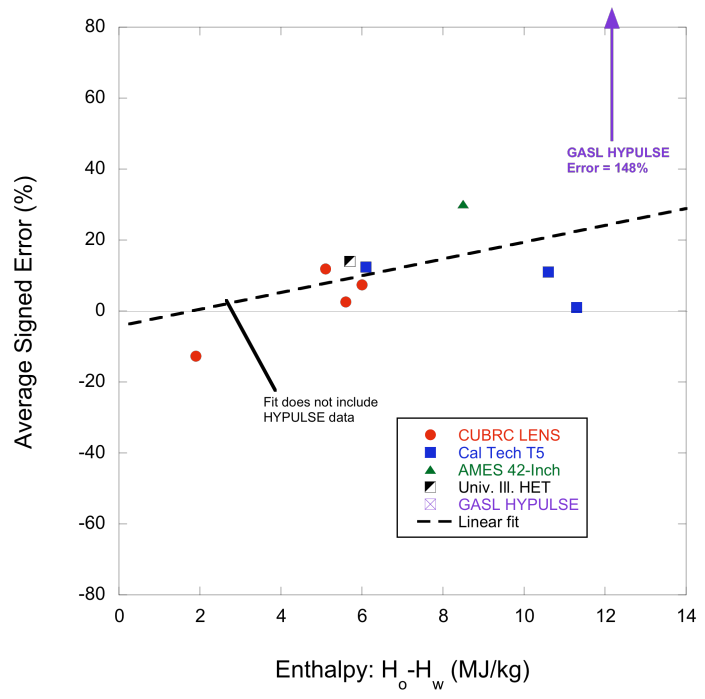

Figure 20. Comparison of super-catalytic predictions to data - averaged signed error

\section{B. Shock-Shape Comparisons}

Comparisons were made between the predicted and measured shock-shapes (with the exception of Caltech Run 2256 for which no image was available) as shown in Figure 21 - Figure 29. The differences between predicted and measured shock stand-off distances at the nose are shown in Figure 30 with respect to total enthalpy and in Figure 31 with respect to free stream density. With the exception of the lowest enthalpy CUBRC LENS case (Series 2, Run 16) and perhaps the ARC 42-Inch case, there were large differences between the predicted and measured shock shapes for all cases. Shock stand-off distances were under-predicted for the CUBRC LENS and GASL HYPULSE cases and over-predicted for the Caltech T5 and University of Illinois HET cases (the available image quality was too low for assessment of the ARC 42-Inch Shock Tunnel case). These comparisons suggest fundamental differences between actual and computed chemical and vibrational relaxation rates, which would strongly influence the predicted surface heating rates. Thus, it cannot be said for certain whether the differences in measured and predicted heating rates were due to the surface catalysis, chemical and vibrational rates (or both) or other factors. And, since high-enthalpy facilities' free-stream conditions are typically determined through a combination of 
diagnostic measurements and numerical methods, it is also possible that the free-stream conditions were not accurately characterized. This possibility is more likely for the reflected shock tunnels, as discussed in Ref. 14 and Ref. 34.

While the focus of this study is primarily on heat-transfer uncertainties, the prediction of shock-shapes also affects aerodynamic uncertainties. The shock shape is an indictor of the surface pressure distribution and thus of the forces and moments resulting from the integration of that pressure distribution. It has been shown (Ref. 34) that the use of different models - Camac (Ref. 35) and Millikan-White (Ref. 36) - for vibrational relaxation rates of the polyatomic $\mathrm{CO}_{2}$ molecule produces an uncertainty in the trim angle of a degree or more for the MSL entry vehicle, which is a significant level for a mission that requires precision entry. The differences in predicted and measured shock shapes for the cases in this study were much larger than those generated for the MSL case in Ref. 34 and so the aerodynamic uncertainties can be expected to be large, however there are no data available for comparisons.

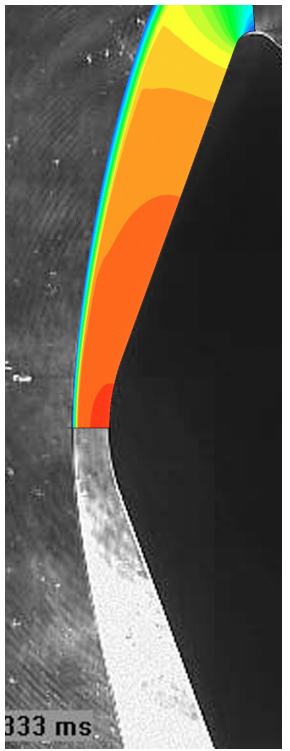

Figure 21. CUBRC LENS I

Reflected Shock Tunnel: Series

2, Run $16-1.9 \mathrm{MJ} / \mathrm{kg}$ case

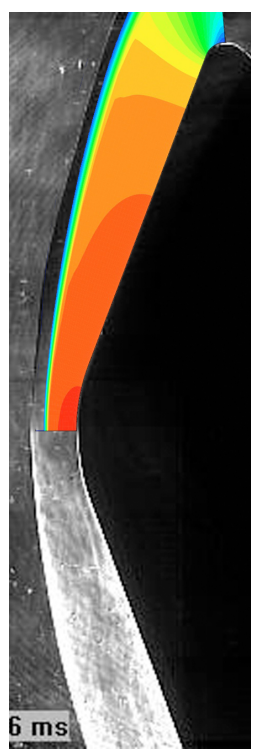

Figure 24. CUBRC LENS I

Reflected Shock Tunnel: Series

2, Run $12-6.0 \mathrm{MJ} / \mathrm{kg}$ case

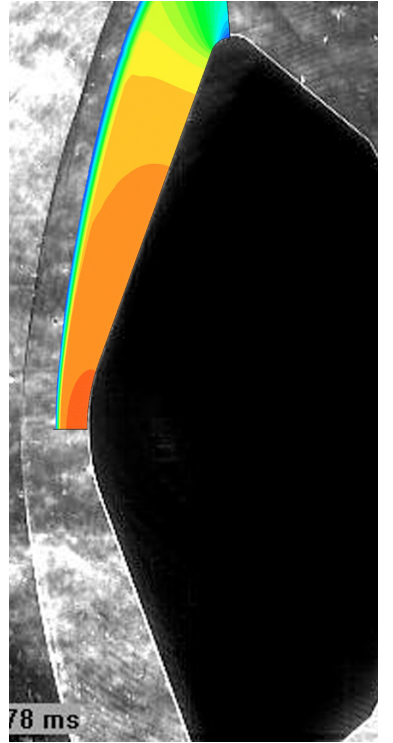

Figure 22. CUBRC LENS I Reflected Shock Tunnel: Series

2, Run 8 - $5.6 \mathrm{MJ} / \mathrm{kg}$ case

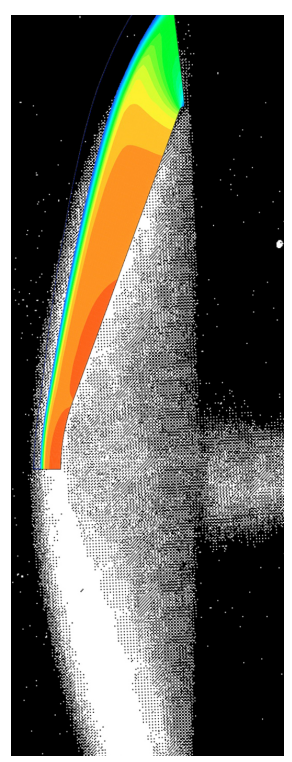

Figure 25. ARC 42-Inch Shock Tunnel - $8.5 \mathrm{MJ} / \mathrm{kg}$ case

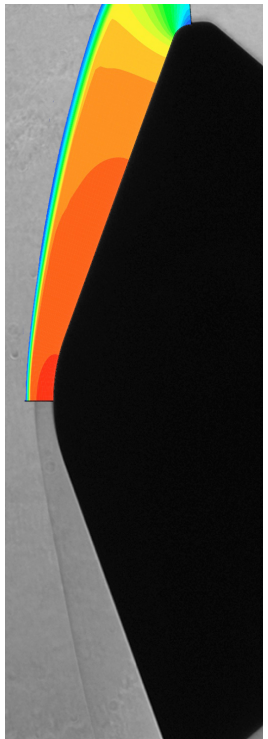

Figure 23. University of Illinois HET Expansion Tube: 5.7 $\mathrm{MJ} / \mathrm{kg}$ case

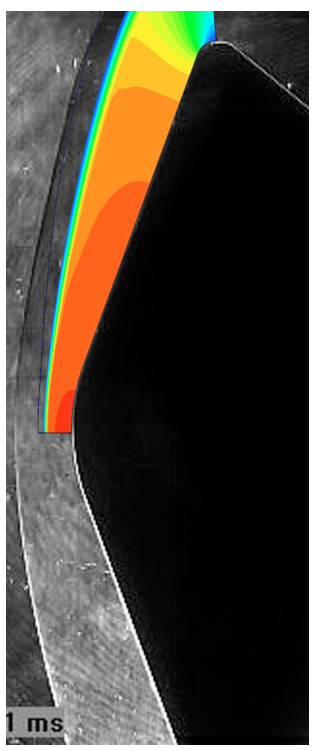

Figure 26. CUBRC LENS I

Reflected Shock Tunnel: Series 2, Run 13 - 8.6 MJ/kg case 


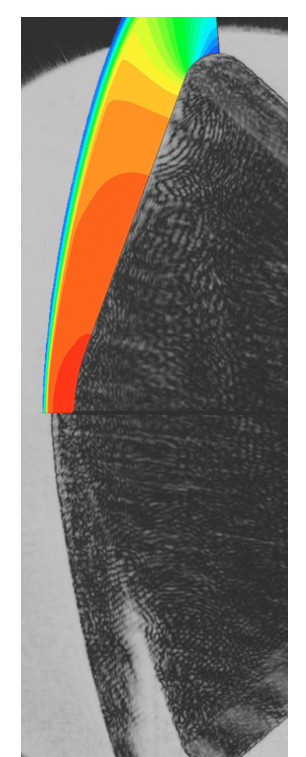

Figure 27. Caltech T5 Reflected

Shock Tunnel:

Run 2254 - 10.6 MJ/kg case

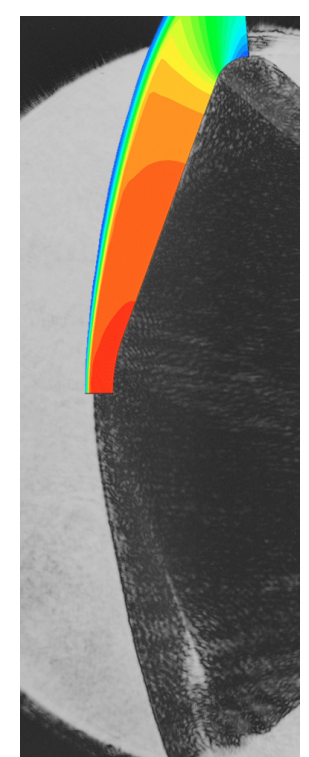

Figure 28. Caltech T5 Reflected

Shock Tunnel:

Run 2255 - 11.3 MJ/kg case

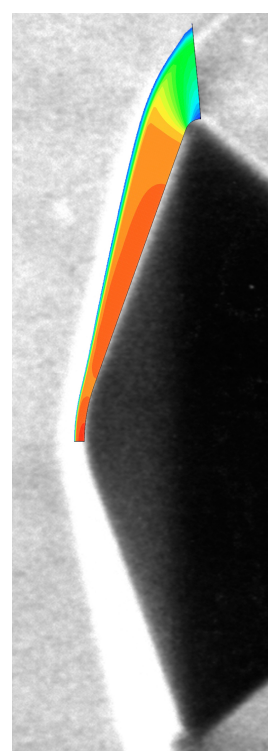

Figure 29. GASL HYPULSE Expansion Tube: Run 749 $12.3 \mathrm{MJ} / \mathrm{kg}$ case

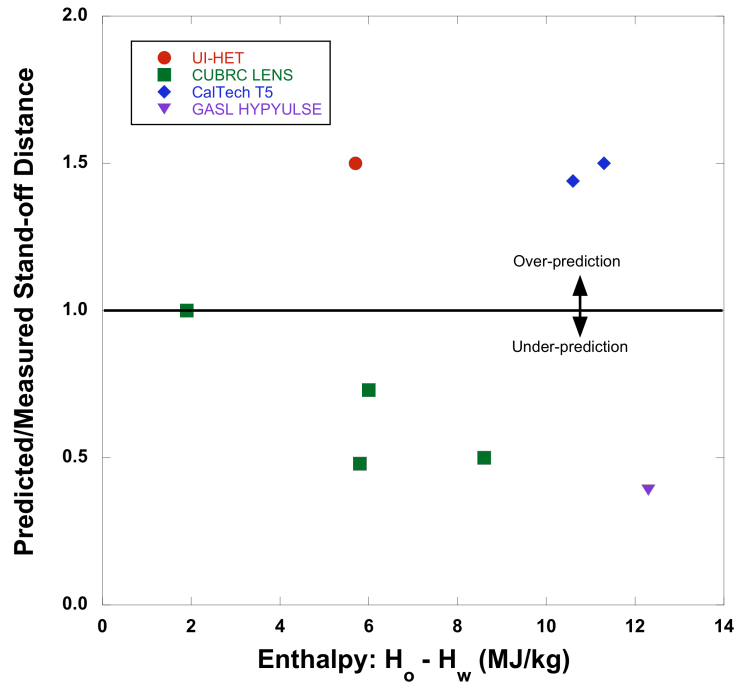

Figure 30. Comparison of Predicted and Measured Shock-Standoff Distances vs. Enthalpy

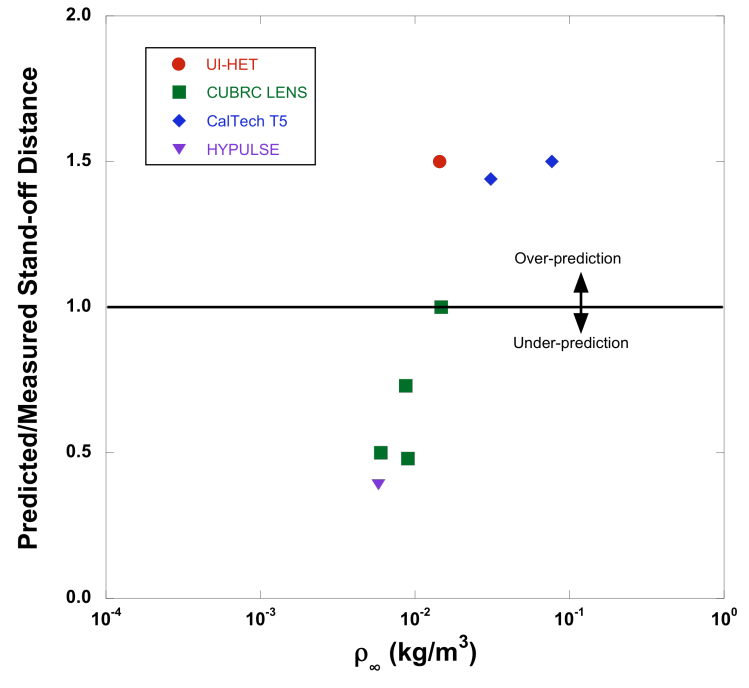

Figure 31. Comparison of Predicted and Measured Shock-Standoff Distances vs. Density

\section{Overall Assessment of Comparisons}

Without attempting to assign the cause to either experimental or computational methods, this survey reveals that very large differences exist between the two with respect to convective aeroheating rates and flow-field shock shapes for high-enthalpy $\mathrm{CO}_{2}$ flows. Differences in heat-transfer rates varied between $15 \%$ and $148 \%$ and were strongly influenced by the selection of surface catalysis models for the computations. Shock stand-off distance comparisons revealed differences ranging from 50\% under-prediction to $50 \%$ over-prediction.

These comparisons are startlingly poor and their implications for Mars exploration missions must be considered. First, in historical context, is the successful Viking mission. Viking peak heating conditions were on the low range of these data, where the uncertainty in heating might be assigned a "reasonable" value in the range of $\pm 20 \%$ based on these comparisons. Off course, neither the data sets reviewed herein nor the computational techniques employed 
existed when that mission was developed. Instead, analytical methods were applied with high levels of conservatism.

In contrast, the MSL mission, for which most of these data sets were developed, is at the high end of the test range. Non-catalytic predictions were up to $\sim 35 \%$ lower than the experimental data while super-catalytic predictions were up to $\sim 35 \%$ higher (excepting the GASL HYPULSE case). It is fortunate that, in fact, the supercatalytic model was employed in the design process since it over-predicts all experimental data except a single lowenthalpy condition.

Looking to the future, HMMES-class missions will experience enthalpies well beyond any existing test data. Since HMMES missions are outside the range of the test data, it cannot safely be assumed that the super-catalytic assumption will provide sufficient conservatism for aeroheating predictions. Additionally, the fact that the predicted and measured shock shapes differ indicates that other phenomena beside wall catalysis are not being modeled properly and may also contribute to aeroheating uncertainties. And, of course, these differences in shock shapes produce an aerodynamic uncertainty that cannot be assessed because there are no relevant force-and-moment data against which to compare predictions.

It is a requirement of this study that some numerical values be assigned to the computational aeroheating uncertainty of the state-of-the-art tools used by NASA for Mars entry problems. While such an assessment is recognized as being overly simplistic, it at least provides a starting point for consideration of the issue. Thus, based on the comparisons presented in Figure 6 - Figure 16, approximate uncertainty estimates for laminar, convective aeroheating have been made in terms of total enthalpy. Because of the previously-noted doubts as to the appropriateness of the super-catalytic boundary conditions, these estimates are based on the averaged error magnitude resulting from the non-catalytic boundary-condition.

- For low enthalpy $(<5 \mathrm{MJ} / \mathrm{kg}): \pm 15 \%$ uncertainty

- For moderate enthalpy $(5 \mathrm{MJ} / \mathrm{kg}$ to $10 \mathrm{MJ} / \mathrm{kg}): \pm 30 \%$ uncertainty

- For high enthalpy $(10 \mathrm{MJ} / \mathrm{kg}$ to $20 \mathrm{MJ} / \mathrm{kg}): \pm 60 \%$ uncertainty

Of course, the overall aeroheating uncertainty must be considerably higher than these values for the laminar, convective uncertainty. Turbulent aeroheating augmentation, shock-layer radiation, and TPS roughness and ablation will also contribute to the aeroheating environment. While some relevant test data do exist on these phenomena, an assessment of their effects cannot be performed until the cause or causes of the existing discrepancies between predictions and measurements illustrated herein have been resolved.

\section{Deficiencies in Current Experimental and Computational Methodologies}

Despite more than 30 years of Mars exploration missions, there has been no comprehensive program to obtain benchmark-quality experimental data on aeroheating in $\mathrm{CO}_{2}$-dominated flows, nor has there been a parallel effort to develop and validate computational methods for Martian entry conditions. While it is true that some testing has been performed in the last decade to support the MSL program, these tests have produced more questions than answers. On the computational side, NASA's two state-of-the-art CFD tools, DPLR and LAURA, are based on the same 1980's-1990's era physical models and differ mainly in algorithmic applications. For a HMMES-class mission to be possible, the current computational uncertainties levels must be better defined and must be greatly reduced. Several avenues of research must be followed to accomplish this task.

First, is the acquisition of flight data. Aerothermodynamic instrumentation must be a requirement for any and all future Mars missions. Both Mars Viking (Refs. 37 - 38) and Mars Pathfinder (Ref. 39) carried some instrumentation, however the data obtained were of limited utility. On a more positive note, the MSL mission will carry a comprehensive flight instrumentation package (Ref. 40 - 41).

Second, is the development and validation of higher-fidelity computational models for physical phenomena, especially for non-equilibrium chemical and vibrational processes and chemical catalysis. Current models are based on the two-temperature approach (Ref. 42) for translational and vibrational modes and have Arrhenius-form chemical rate expressions fitted to these temperatures (e.g. Ref. 29). However, the validity of the two-temperature approach has been called into question (Ref. 43) and investigations of new thermophysical models have begun (e.g. Refs. 44 - 45). It is important that development of such models take into account not only flight-relevant conditions, but also ground-test conditions in order to provide some anchor-point for model validation.

Finally, more ground-test data is required and the requirements for future testing will be dealt with in greater depth. With respect to the existing data sets, several deficiencies can be identified that must be addressed in future testing:

1) As detailed in Table 1, data were obtained across a fairly wide range of conditions in the five different facilities, but there was no overlap of test conditions between the facilities. It is most notable that densities in the Caltech T5 test, in which shock stand-off distances were over-predicted, were an order-of-

14

American Institute of Aeronautics and Astronautics 
magnitude higher than those of the CUBRC LENS test, in which shock stand-off distances were underpredicted. This observation suggests a possible connection since chemical and vibrational processes will be influenced by density, however other factors must also be considered. An overlap in test conditions in multiple facilities should be a requirement for future testing.

2) Testing was not conducted in any of the individual facilities across a wide enough range of test conditions to generate significant differences in the flow field environments in any one facility. Future tests should span an enthalpy range in each facility sufficient to encompass both perfect (or near-perfect) gas and chemically-reacting gas conditions in order produce a wide range of chemical reaction rates, as well as densities sufficient to encompass both equilibrium and non-equilibrium conditions. This requirement will help identify trends in the physical processes (such as catalysis, vibrational relaxation and chemical reaction rates) and to validate the operational characteristics of the facilities.

3) The heat-transfer instrumentation types were not consistent from facility to facility. Thin-film gages, coaxial thermocouples, surface thermocouples and calorimeters were all employed. While some variation in instrumentation is desirable to provide independent quality checks, at least one common type of instrumentation should be employed in all tests.

4) While the evidence is not conclusive, it has been hypothesized (e.g. Ref. 34) that the operating conditions of the reflected-shock tunnels (Ames 42-Inch, CUBRC LENS, Caltech T5) may have been influenced by non-equilibrium vibrational and/or chemical excitation that was not properly characterized. Theoretically, shock-expansion tunnels will be less prone to such difficulties and testing should be concentrated on such facilities, although the use of reflected-shock tunnels should be not completely rejected. However, the process of characterizing the flow field in any high-enthalpy facility is complicated by the fact that the CFD tools for which validation data are sought are also being used to determine the free-stream conditions of the tests being performed to generate validation data. Thus, an iterative process will be required to develop and validate models for both the facility operational processes and the resulting flow around the test article.

5) The catalytic properties of the wind tunnel models were not conclusively established. The tentative assumption is that the metallic models used in all tests except GASL HYPULSE were non-catalytic. For the HYPULSE test, this assumption is even more credible since the models were fabricated from Macor ceramic. It should be a requirement for future testing that independent analyses are conducted to determine the catalytic properties of both the wind tunnel model materials and of the instrumentation (i.e. thin-film or thermocouple surfaces).

6) The thermo-physical properties of the wind tunnel model materials (i.e. thermal diffusivity and thermal conductivity) must be better characterized. Uncertainties in these properties have a direct linear effect on the conduction analyses performed to determine heat transfer rates from the measured temperature-time histories. Unfortunately, this information is rarely documented in test reports, even though some studies have identified significant uncertainties in the available literature (e.g. Refs. 8, 46).

7) All testing to-date has been performed at "cold-wall" conditions where wall temperatures remain relatively unchanged (with respect to flow field total temperature) due to the brief duration of highenthalpy facility runs. If possible, some testing should be performed with models pre-heated to an elevated temperature; this requirement may provide some insight into chemical and catalytic behavior at the wall.

\section{Summary and Conclusions}

Future Mars exploration missions under consideration by NASA will require the development of High-Mass Mars Entry Systems. These systems will have masses an order-of-magnitude greater than those of previous missions, and will experience much more severe aerothermodynamic entry environments. In order to support the future development of these systems, a survey was conducted to identify sources of high-enthalpy, $\mathrm{CO}_{2}$ aerothermodynamic data that could be used to help define computational uncertainties in state-of-the-art flow-field prediction tools employed by NASA.

Comparisons were performed between these experimental data and computational predictions generated for this study. Large differences were found to exist for both surface heat-transfer rates and flow field shock shapes. Estimates for the uncertainty in computational aeroheating predictions ranged from $\pm 15 \%$ at low enthalpy $(<5$ $\mathrm{MJ} / \mathrm{kg}$ ) to $\pm 60 \%$ at high-enthalpy ( $>10 \mathrm{MJ} / \mathrm{kg}$ ). However, the scope of the data sets was not sufficient to perform rigorous uncertainty analyses. Several factors were found to influence these results, including: the correct modeling of surface catalysis; the proper definition of free-stream test conditions; and numerical modeling of vibrational 
relaxation rates for $\mathrm{CO}_{2}$. Large discrepancies in predicted and measured shock shapes were also identified. While experimental aerodynamic data were not available to evaluate the integrated effects of these shock-shape differences, they are large enough to be of concern when accurate guidance for precision landing is required.

These results of this study are intended to aid in the development of guidelines for future NASA investments in experimental and computational research toward decreasing entry-vehicle design uncertainties and margins for future Mars missions. Specific requirements for future experimental aerothermodynamic have been provided. Additional research will be required to better define, and ultimately reduce, these uncertainties.

\section{Acknowledgements}

This work was supported by the NASA Fundamental Aeronautics Program, Hypersonics Project. The authors wish to thank the other members of the Uncertainty Assessment Task Force for their contributions and discussions: Deepak Bose and Jim Brown at NASA Ames Research Center and Scott Berry, Peter Gnoffo and Chris Johnston at NASA Langley Research Center. The authors also wish to acknowledge the original work performed by the researchers who generated the data presented herein, including: Dave Stewart, Y. K. Chen, and Michael Wright at NASA Ames, Michael Holden, Matt MacLean and Tim Wadhams at CUBRC LENS, and Manu Sharma at the University of Illinois.

\section{References}

${ }^{1}$ Cianciolo, A. M., Davis, J. L., Komar, D. R., et al, "Entry, Descent and Landing Systems Analysis Study: Phase 1 Report," NASA TM-2010-216720, July 2010.

${ }^{2}$ Bose, D., Brown, J., Prabhu, D. K., Gnoffo, P., Johnston, C. J., and Hollis, B., "Uncertainty Assessment of Hypersonic Aerothermodynamics Prediction Capability," to be presented at the AIAA Thermophysics Conference, Honolulu, HI, June 27-30, 2011.

${ }^{3}$ Wright, M. J., Tang, C. Y., Edquist, K. T., Hollis, B. R., Krasa, P. and Campbell, C. A., "A Review of Aerothermal Modeling for Mars Entry Missions," AIAA Paper 2010-0443, 48 ${ }^{\text {th }}$ AIAA Aerospace Sciences Meeting, Orlando, FL, January 4-7, 2010.

${ }^{4}$ Bose, D., Wright, M. J., and Palmer, G. E., "Uncertainty Analysis of Laminar Aeroheating Predictions for Mars Entries," Journal of Thermophysics and Heat Transfer, Vol. 20, No. 4, October-December 2006, pp. 652-662.

${ }^{5}$ Stewart, D. A. and Chen, Y. K., "Hypersonic Convective Heat Transfer over 140-deg Blunt Cones in Different Gases," Journal of Spacecraft and Rockets, Vol. 31, No. 5, September-October 1994, pp. 735-743.

${ }^{6}$ Hollis, B. R. and Perkins, J. N., "High-Enthalpy Aerothermodynamics of a Mars Entry Vehicle, Part 1: Experimental Results," Journal of Spacecraft and Rockets, Vol. 34, No. 4, July-August 1997, pp. 449-456.

${ }^{7}$ Hollis, B. R. and Perkins, J. N., "High-Enthalpy Aerothermodynamics of a Mars Entry Vehicle, Part 2: Computational Results," Journal of Spacecraft and Rockets, Vol. 34, No. 4, July-August 1997, pp. 457-463.

${ }^{8}$ Hollis, B. R. "Experimental and Computational Aerothermodynamics of a Mars Entry Vehicle," NASA CR-201633, December 1996.

${ }^{9}$ Wright, M. J., Olejniczak, J., Brown, J. L., Hornung, H. G., and Edquist, K. T.,” Modeling of Shock Tunnel Aeroheating Data on the Mars Science Laboratory Aeroshell," Journal of Thermophysics and Heat Transfer, Vol. 20, No. 4, October-December 2006, pp. 641-651.

${ }^{10}$ Olejniczak, J., Wright, M. J., Laurence, S., and Hornung, H. G., "Computational Modeling of T5 Laminar and Turbulent Heating Data on Blunt Cones, Part 1: Titan Applications," AIAA Paper 2005-0176, $43^{\text {rd }}$ AIAA Aerospace Sciences Meeting and Exhibit, Reno, NV, January 10-15, 2005.

${ }^{11}$ Hollis, B. R., Liechty, D. S., Wright, M. J., Holden, M. S., Wadhams, T. P., MacLean, M. and Dyakonov, A., "Transition Onset and Turbulent Heating Measurements for the Mars Science Laboratory Entry Vehicle," AIAA Paper 2005-1437, 43 ${ }^{\text {rd }}$ AIAA Aerospace Sciences Meeting and Exhibit, Reno, NV, January 10-15, 2005.

${ }^{12}$ MacLean, M., Wadhams, T., Holden, M. and Hollis, B. R., "Investigation of Blunt Bodies with $\mathrm{CO}_{2}$ Test Gas Including Catalytic Effects," AIAA Paper 2005-4693, 38 ${ }^{\text {th }}$ AIAA Thermophysics Conference, Toronto, Ontario, June 6-9, 2005.

${ }^{13}$ MacLean, M. and Holden, M., "Catalytic Effects on Heat Transfer Measurements for Aerothermal Studies with $\mathrm{CO}_{2}, " 44^{\text {th }}$ AIAA Aerospace Sciences Meeting and Exhibit, Reno, NV, January 9-12, 2006.

${ }^{14}$ Sharma, M., Swantek, A. B., Flaherty, W., Austin, J. M., Doraiswamy, S. and Candler, G. V., "Experimental and Numerical Investigation of Hypervelocity Carbon Dioxide Flow over Blunt Bodies," Journal of Thermophysics and Heat Transfer, Vol. 24, No. 4, October-November 2010, pp. 673-683.

${ }^{15}$ Muylaert, J., Kumar, A., and Dujarric, C. (eds.), Hypersonic Experimental and Computational Capability, Improvement and Validation, AGARD Advisory Report 319 Vol. II, December 1998.

${ }^{16}$ Moss, J. N. and Lengrand, J. C., "Chapter 3: Rarefied Flow", Hypersonic Experimental and Computational Capability, Improvement and Validation, Muylaert, J., Kumar, A., and Dujarric, C. (eds.), AGARD Advisory Report 319 Vol. II, December 1998. 
${ }^{17}$ Deiwert, G. S. and Eitelberg, G. "Chapter 4: Real Gas / Blunt Cone Phase II Report”, Hypersonic Experimental and Computational Capability, Improvement and Validation, Muylaert, J., Kumar, A., and Dujarric, C. (eds.), AGARD Advisory Report 319 Vol. II, December 1998.

${ }^{18}$ Kastell, D., Rosenhauer, M., Wollenhaupt, M., Müller T., Krek, R., Beck, W., and Eitelberg, G., "Study of Aerochemistry Around a 70-deg Half Angle Blunted Cone in the High Enthalpy Shock Tunnel, Part 1: Preparation of the Tests," Deutsche Forschungsanstalt für Luft-und Raumfarht, Forschungsbericht, DLR-IB 223-95 C17, 1995.

${ }^{19}$ Kastell, D., Krek, R., Rosenhauer, M., Wollenhaupt, M., Müller, T., Beck, W., and Eitelberg, G., "Study of Aerochemistry Around a 70-deg Half Angle Blunted Cone in the High Enthalpy Shock Tunnel, Part 2: Results," Deutsche Forschungsanstalt für Luft-und Raumfarht, Forschungsbericht, DLR-IB 223-95 C41, 1995.

${ }^{20}$ Kastell, D., "Aerodynamik eines stumpfen Kegels in reagierender Überschallströmung (Aerodynamics of a Blunted Cone in Reacting Hypersonic Flows)," Deutsche Forschungsanstalt für Luft-und Raumfarht, Forschungsbericht 97-06, ISRN DLR-FB97-06 and ISSN 0939-2963, 1997.

${ }^{21}$ Holden, M., Harvey. J., Body, I., George, J., and Horvath T., "Experimental and Computational Studies of the Flow Over a Sting Mounted Planetary Probe Configuration," AIAA Paper 199-0768, 35 ${ }^{\text {th }}$ Aerospace Sciences Meeting and Exhibit, Reno, NV, January 6-10, 1997.

${ }^{22}$ Gnoffo, P. A., "An Upwind Biased, Point-Implicit Relaxation Algorithm for Viscous, Compressible Perfect-Gas Flows," NASA TP-2953, 1990.

${ }^{23}$ Mazaheri, Alireza, Gnoffo, P. A., Johnston, C. O., and Kleb, W., “LAURA Users Manual: 5.3-48528," NASA TM-2010216386, August 2010.

${ }^{24}$ Wright, M. J., Candler, G. V. and Bose, D., "Data-Parallel Line Relaxation Method for the Navier-Stokes Equations, "AIAA Journal, Vol. 36, No. 9, November 1998, pp. 1603-1609.

${ }^{25}$ Wright, M. J., White, T. and Mangini, N., "Data Parallel Line Relaxation (DPLR) Code User Manual Acadia - Version 4.01.1," NASA-TM-2009-215388, October 2009.

${ }^{26}$ Edquist, K. T., Dyakonov, A. A., Wright, M. J., and Tang, C. Y., “Aerothermodynamics Environments Definition for the Mars Science Laboratory Entry Capsule," AIAA Paper 2007-1206, 45 ${ }^{\text {th }}$ AIAA Aerospace Sciences Meeting and Exhibit, Reno, NV, January 8-11, 2007.

${ }^{27}$ Hash, D., Olejniczak, J., Wright, M. J., et al, "FIRE II Calculations for Hypersonic Nonequilibrium Aerothermodynamics Code Verification: DPLR, LAURA and US3D," AIAA Paper 2007-0605, 45 ${ }^{\text {th }}$ AIAA Aerospace Sciences Meeting and Exhibit, Reno, NV, January 8-11, 2007.

${ }^{28}$ Park, C., Howe, J. T., Jaffe, R. L. and Candler, G. V., "Review of Chemical-Kinetic Problems of Future NASA Missions, II: Mars Entries," Journal of Thermophysics and Heat Transfer, Vol. 8, No. 1, January - March 1994, pp. 9-23.

${ }^{29}$ Park, C., Jaffe R. L., and Partridge, H., "Chemical-Kinetic Parameters of Hyperbolic Earth Entry," Journal of Thermophysics and Heat Transfer, Vol. 15, No. 1, January - March 2001, pp. 76-90.

${ }^{30}$ Fujita, K., Yamada, T., and Nobuyuki, I., "Impact of Ablation Gas Kinetics on Hyperbolic Entry Radiative Heating," AIAA Paper 2006-1185, 44 ${ }^{\text {th }}$ AIAA Aerospace Sciences Meeting and Exhibit, Reno, NV, January 9-12, 2006.

${ }^{31}$ Evans, J. S., Schexnayder, C. J., and Grose, W. L., "Effects of Nonequilibrium Ablation Chemistry on Viking Radio Blackout", Journal of Spacecraft and Rockets, Vol. 11, No. 2, February, 1974, pp. 84-88.

${ }^{32}$ Gnoffo, P. A., Gupta, R. N., and Shinn, J. L., "Conservation Equations and Physical Models for Hypersonic Air Flow in Thermal and Chemical Nonequilibrium," NASA TP-2867, February, 1989.

${ }^{33}$ Edquist, K. T., Dyakonov, A. A., Wright, M. J., and Tang, C. Y., “Aerothermodynamic Design of the Mars Science Laboratory Heatshield," AIAA Paper 2009-4075, $41^{\text {st }}$ AIAA Thermophysics Conference, San Antonio, TX, June 22-25, 2009.

${ }^{34}$ MacLean, M. and Holden, M. "Numerical Assessment of Data in Catalytic and Transitional Flows for Martian Entry," AIAA Paper 2006-2946, $9^{\text {th }}$ AIAA/ASME Joint Thermophysics and Heat Transfer Conference, San Francisco, CA, June 5-8, 2006.Schoenenberger, M., Dyakonov, A., Buning, P., Scallion, W. and Van Norman, J., "Aerodynamic Challenges for the Mars Science Laboratory Entry, Descent and Landing," AIAA Paper 2009-3914, $41^{\text {st }}$ AIAA Thermophysics Conference, San Antonio, TX, June 22-25, 2009.

${ }^{35}$ Camac, M. "CO2 Relaxation Process in Shock Waves," in Fundamental Phenomena in Hypersonic Flows, ed. Hall, J. G., Cornell University Press, Ithaca, NY, 1966.

${ }^{36}$ Millikan, R. C. and White, D. R., "Systematics of Vibrational Relaxation," Journal of Chemical Physics, Vol. 39, No. 12, December, 1963, pp. 3209-3213.

${ }^{37}$ Edquist, K. T., Wright, M. J., and Allen, G. A., "Viking Afterbody Heating Computations and Comparisons to Flight Data," AIAA Paper 2006-0386, $44^{\text {th }}$ AIAA Aerospace Sciences Meeting and Exhibit, Reno, NV, January 9-12, 2006.

${ }^{38}$ Edquist, K. T., "Computations of Viking Lander Capsule Hypersonic Aerodynamics with Comparisons to Ground and Flight Data," AIAA Paper 2006-6137, AIAA Atmospheric Flight Mechanics Conference and Exhibit, Keystone, CO, August 21 - 24 , 2006.

${ }^{39}$ Milos, F. S., Chen, Y. K., Congdon, W. M., and Thronton, J. M., "Mars Pathfinder Entry Temperature Data, Aerothermal Heating, and Heatshield Material Response," Journal of Spacecraft and Rockets, Vol. 36, No. 3, May-June 1999, pp. 380 - 391.

${ }^{40}$ Gazarik, M. J., Wright, M. J., Little, A., Cheatwood, F. M., Herath, J. A., Munk, M. M., Novak, F. J., and Martinez, E. R., "Overview of the MEDLI Project," IEEE 2008 Aerospace Conference, March 2008.

${ }^{41}$ Karlgaard, C. D., Beck, R. E., O’Keefe, S. A, Siemers, P. M., White, B. A., Engelund, W. C., and Munk, M. M., "Mars Entry Atmospheric Data System Modeling and Algorithm Development," AIAA Paper 2009-3916, 41 ${ }^{\text {st }}$ AIAA Thermophysics Conference, San Antonio, TX, June 22 - 25, 2009. 
${ }^{42}$ Park, C., "Assessment of Two-Temperature Kinetic Model for Ionizing Air," Journal of Thermophysics and Heat Transfer, Vol. 3, No. 3, July 1989, pp. 233-244.

${ }^{43}$ Park, C., "The Limits of Two-Temperature Model," AIAA Paper 2010-0911, 48 ${ }^{\text {th }}$ AIAA Aerospace Sciences Meeting, Orlando, FL, January 4-7, 2010.

${ }^{44}$ Candler, G. V., Doraiswamy, S., and Kelley, J. D., "The Potential Role of Electronically-Excited States in Recombining Flows," AIAA Paper 2010-0912, 48 ${ }^{\text {th }}$ AIAA Aerospace Sciences Meeting, Orlando, FL, January 4-7, 2010.

${ }^{45}$ Doraiswamy, S. Kelley, J. D., and Candler, G. V.," Analysis of Chemistry-Vibration Coupling in Diatomics for High-Enthalpy Nozzle Flows," AIAA Paper 2010-1570, 48 ${ }^{\text {th }}$ AIAA Aerospace Sciences Meeting, Orlando, FL, January 4-7, 2010.

${ }^{46}$ Coblish, J. J., Coulter, S. M., and Norris, J. D., "Aerothermal Measurement Improvements using Coaxial Thermocouples at AEDC Hypervelocity Wind Tunnel No. 9", AIAA Paper 2007-1467, 45 ${ }^{\text {th }}$ AIAA Aerospace Sciences Meeting and Exhibit, Reno, NV, January 8-11, 2007. 